\title{
Aerosol optical and microphysical retrievals from a hybrid multiwavelength lidar data set - DISCOVER-AQ 2011
}

\author{
P. Sawamura ${ }^{1,5,{ }^{*} \text {, D. Müller }}{ }^{3}$, R. M. Hoff ${ }^{2}$, C. A. Hostetler ${ }^{1}$, R. A. Ferrare ${ }^{1}$, J. W. Hair ${ }^{1}$, R. R. Rogers ${ }^{1}$, \\ B. E. Anderson ${ }^{1}$, L. D. Ziemba ${ }^{1}$, A. J. Beyersdorf ${ }^{1}$, K. L. Thornhill ${ }^{1}$, E. L. Winstead ${ }^{1}$, and B. N. Holben ${ }^{4}$ \\ ${ }^{1}$ NASA Langley Research Center, Hampton, VA 23681, USA \\ ${ }^{2}$ University of Maryland, Baltimore County, Baltimore, MD 21250, USA \\ ${ }^{3}$ University of Hertfordshire, College Lane, Hatfield, Herts, AL 10 9AB, UK \\ ${ }^{4}$ NASA Goddard Space Flight Center, Greenbelt, MD 20771, USA \\ ${ }^{5}$ Oak Ridge Associated Universities (ORAU), Oak Ridge TN 37831, USA \\ * formerly at: University of Maryland, Baltimore County, Baltimore, MD 21250, USA
}

Correspondence to: P. Sawamura (patricia.sawamura@nasa.gov)

Received: 20 February 2014 - Published in Atmos. Meas. Tech. Discuss.: 28 March 2014

Revised: 28 July 2014 - Accepted: 22 August 2014 - Published: 24 September 2014

\begin{abstract}
Retrievals of aerosol microphysical properties (effective radius, volume and surface-area concentrations) and aerosol optical properties (complex index of refraction and single-scattering albedo) were obtained from a hybrid multiwavelength lidar data set for the first time. In July 2011, in the Baltimore-Washington DC region, synergistic profiling of optical and microphysical properties of aerosols with both airborne (in situ and remote sensing) and ground-based remote sensing systems was performed during the first deployment of DISCOVER-AQ. The hybrid multiwavelength lidar data set combines ground-based elastic backscatter lidar measurements at $355 \mathrm{~nm}$ with airborne High-SpectralResolution Lidar (HSRL) measurements at $532 \mathrm{~nm}$ and elastic backscatter lidar measurements at $1064 \mathrm{~nm}$ that were obtained less than $5 \mathrm{~km}$ apart from each other. This was the first study in which optical and microphysical retrievals from lidar were obtained during the day and directly compared to AERONET and in situ measurements for 11 cases. Good agreement was observed between lidar and AERONET retrievals. Larger discrepancies were observed between lidar retrievals and in situ measurements obtained by the aircraft and aerosol hygroscopic effects are believed to be the main factor in such discrepancies.
\end{abstract}

\section{Introduction}

Aerosols are known to play an important role in chemical processes, cloud formation, air quality, radiative balance, and other atmospheric processes. In the last few decades, great progress has been achieved towards a better understanding of the optical and physical properties of aerosols, as well as of how changes in those properties affect the atmospheric radiative processes. Currently, many instruments onboard satellites allow for retrievals of column-integrated properties of aerosols on a daily basis (Tanré et al., 1997; Kaufman et al., 1997; Knapp, 2002; Liu et al., 2014). In addition to satellites, a number of ground-based networks contribute continuous aerosol observations (Holben et al., 1998; Bösenberg et al., 2003; Welton et al., 2001; Sugimoto and Uno, 2009). However, despite this continuous advance, it is indisputable that many gaps in our understanding of aerosols are yet to be filled.

Aerosols originate both naturally and from anthropogenic processes. Globally, more than half of all particle emissions are of anthropogenic origin (Jacobson, 2012). These particles enter the atmosphere through emissions and nucleation. While suspended in the atmosphere, the sizes of these particles, as well as their number distributions, evolve as they undergo coagulation, condensation, water uptake, chemical reactions, and removal processes. 
The sizes and types of aerosols can display large variations both in spatial and temporal scale. Therefore, a continuous effort to monitor the particles present in the boundary layer is necessary.

An important aspect with regard to how these particles affect our climate is that the radiative forcing due to aerosols depends on their vertical distribution. For instance, due to hygroscopic growth effects, scattering particles produce a greater forcing when the majority of aerosol particles are located in the lower troposphere, whereas absorbing particles will produce a greater forcing above clouds/cloudy layers or when the underlying surface albedo is high (Haywood and Ramaswamy, 1998). Also, surface temperature and climate responses depend on both vertical and horizontal distribution of aerosols (Hansen et al., 1997). For that reason, a proper characterization of the vertical distribution of aerosols is necessary.

\section{Motivation}

Retrievals based on the inversion of multispectral radiance measurements obtained by ground-based and spaceborne radiometers are representative of the entire atmospheric column and therefore do not provide information on how the aerosols are distributed throughout the column. Lidars, on the other hand, are capable of determining the vertical distribution of aerosols with high spatial and temporal resolution. Several ground-based lidar networks across the globe, such as the European Aerosol Research Lidar Network (EARLINET: Bösenberg et al., 2003), the Micropulse Lidar Network (MPLNET: Welton et al., 2001), and the Asian Dust Network (ADNet: Sugimoto and Uno, 2009), contribute to regular aerosol observations.

Over the past decade, the development of inversion techniques for the retrieval of microphysical properties (such as effective radius, number, surface-area and volume concentrations) and optical parameters (such as absorption and scattering coefficients, single-scattering albedo, and complex index of refraction) from multiwavelength lidar systems has brought a new perspective to the study of the vertical distribution of aerosols (Müller et al., 1998, 1999a, b).

More specifically, the recommended multiwavelength lidar data set necessary to obtain such retrievals consists of a set of backscatter coefficients $(\beta)$ at 355, 532 and $1064 \mathrm{~nm}$ and a set of extinction coefficients $(\alpha)$ at 355 and $532 \mathrm{~nm}$ (Veselovskii et al., 2002; Böckmann et al., 2005), which are the usual wavelength outputs from a Nd: YAG laser.

All microphysical retrievals from multiwavelength lidar data obtained to date, however, originated from ground-based Raman lidar systems. Raman lidars are capable of measuring elastic backscatter signals due to molecules and particles in the atmosphere as well as inelastic backscatter signals due to molecules (oxygen and/or nitrogen). These systems are therefore capable of providing independent measurements of extinction and backscatter coefficients without the need for an assumption of extinction-to-backscatter ratio (i.e., lidar ratio). However Raman lidars suffer from one major drawback: they are generally limited to nighttime operations due to the weak Raman backscattering signal, which makes it very sensitive to solar background radiation. Therefore it can be very difficult to characterize the aerosol variation throughout the day with Raman lidar systems. Wandinger et al. (2002) compared nighttime lidar retrievals of effective radius, volume and surface-area concentrations, complex index of refraction, and single-scattering albedo with nighttime airborne in situ measurements for two cases and obtained good agreement during LACE 98. In this study, good agreement $(<30 \%)$ was obtained between the lidar retrievals and the in situ measurements for cases of aerosols that originated from forest fires. Veselovskii et al. (2009) compared early nighttime retrievals of mean and effective radius, Ångström exponent, complex index of refraction, and number and volume concentrations with late daytime AERONET (Aerosol Robotic Network) retrievals for three cases under varying relative humidity conditions. Good agreement was obtained between lidar retrievals and AERONET retrievals of the fine mode of the particle size distribution.

Moreover, most lidar-based aerosol microphysical characterization efforts have taken place in either Europe (Müller et al., 2001, 2003, 2011; Wandinger et al., 2002; Veselovskii et al., 2002; Balis et al., 2010) or East Asia (Murayama et al., 2004; Müller et al., 2006; Tesche et al., 2008; Noh et al., 2009, 2011; Noh, 2014). In the United States there is a shortage of multiwavelength lidar systems that are able to provide good quality backscatter and extinction profiles at the aforementioned wavelengths. Therefore, only a very limited number of case studies have been performed in the US (Veselovskii et al., 2009, 2012a, b), and all of them utilized one Raman lidar instrument.

In this work we obtained, for the first time to our knowledge, retrievals of optical and microphysical properties of aerosols using a hybrid multiwavelength lidar data set which consists of the combination of both elastic and High-Spectral-Resolution Lidar (HSRL) techniques as well as ground-based and airborne measurement platforms. Elastic lidar measurements were obtained by a ground-based system at $355 \mathrm{~nm}$ and an airborne system operating at $1064 \mathrm{~nm}$. HSRL measurements at $532 \mathrm{~nm}$ were also carried out with the airborne system (onboard the NASA UC-12 aircraft). In addition to being the first time that retrievals of this kind have been obtained from a combination of ground-based and airborne elastic and HSRL measurements, it is also the first study of this kind, to our knowledge, in which all lidar measurements have been obtained during daytime.

Retrievals of effective radius, volume and surface-area concentrations, the complex refractive index, and singlescattering albedo were obtained from the inversion of the hybrid multiwavelength lidar data set utilizing the inversion algorithm described by Müller et al. (1999a, b). 




Figure 1. Map of the Baltimore-Washington DC region with the locations considered for the lidar retrievals comparison to AERONET retrievals and in situ airborne measurements during DISCOVERAQ.

The data utilized in this work were obtained during the first deployment of DISCOVER-AQ (Deriving Information on Surface conditions from Column and Vertically Resolved Observations Relevant to Air Quality), which took place in the Baltimore-Washington DC corridor in July 2011. The DISCOVER-AQ project is a 5-year field experiment funded by the NASA Earth Venture program. The goal of DISCOVER-AQ is to improve our understanding on how to relate total-column observations with near-surface conditions of aerosol and trace gases (Hoff et al., 2012; DISCOVERAQ, 2011).

During this campaign a number of ground-based and airborne instruments were deployed throughout the BaltimoreWashington DC region, providing the data necessary to construct the hybrid multiwavelength lidar data set. Optical and physical parameters of aerosols from airborne in situ instruments (onboard the P-3B aircraft) and ground-based sunphotometers were also obtained during this experiment and compared with our lidar retrievals. Figure 1 shows a map with the locations of interest during this study.

The hybrid lidar data set and the inversion methodology are described in more detail in Sect. 3. Discussion of the results and comparison of the lidar retrievals with airborne in situ measurements and AERONET inversion products are presented in Sect. 4.

\section{Methodology}

\subsection{DISCOVER-AQ and case studies selection}

During the first deployment of DISCOVER-AQ, 16 flights were conducted with the P-3B aircraft and 14 with the UC12 from 28 June to 29 July in the Baltimore-Washington DC area. The P-3B aircraft carried a number of in situ instruments, while the UC-12 carried the HSRL system (Hair et al., 2008).

The P-3B flew in ascending/descending spirals over a number of locations in order to obtain vertical profiles of in situ measurements of optical, physical, and chemical properties of aerosols. The P-3B aircraft carried two threewavelength integrating nephelometers (TSI model 3563), an Ultra-High-Sensitivity Aerosol Spectrometer (UHSAS) and a Particle Soot Absorption Photometer (PSAP), as well as other particle counters and instruments that measured the aerosols chemical composition. The UHSAS obtained size distribution of the aerosols within the size range of $60 \mathrm{~nm}$ to $1 \mu \mathrm{m}$ in diameter. The two nephelometers ran in parallel, with one being operated under dry conditions with relative humidity (RH) of less than $40 \%$, and the other operating at a nominal RH of $80 \pm 4 \%$ (Ziemba et al., 2013). The combination of measurements from the nephelometer at $550 \mathrm{~nm}$ and the PSAP at $532 \mathrm{~nm}$ allowed for the calculation of singlescattering albedo profiles, i.e., scattering-to-extinction ratio profiles, which were compared to lidar retrievals of singlescattering albedo at $532 \mathrm{~nm}$.

AERONET sunphotometers were also deployed on the ground. AERONET is a global network of sun-sky radiometers that provides measurements of aerosol optical and microphysical properties in the total atmospheric column from direct and diffuse radiation at multiple wavelengths (Holben et al., 1998). Since 2011 the Distributed Regional Aerosol Gridded Observation Networks (DRAGON) has been deployed in many field campaigns in order to provide a more extensive yet regionally dense AERONET-like data set to address satellite validation and in situ comparisons (Holben et al., 2011). DISCOVER-AQ 2011 was the first field campaign in which DRAGON was deployed. For this study we utilized data obtained at DRAGON stations in Beltsville, Essex, and Padonia (which are here referred to as AERONET stations), and we also utilized AERONET data obtained at UMBC.

With respect to data quality, AERONET releases its aerosol products as level 1.5 (cloud screened) and 2.0 (cloud screened and quality assured). A number of criteria must be met for the retrievals to be accepted as level 1.5 and then level 2.0. These criteria are presented in detail by Holben et al. (2006). In particular, retrievals of single-scattering albedo $\left(\omega_{0}\right)$ and complex index of refraction $(m)$ are only "quality assured" (level 2.0) when the aerosol optical depth (AOD) value at $440\left(\tau_{440}\right)$ is greater than or equal to 0.40 (Dubovik et al., 2000). 


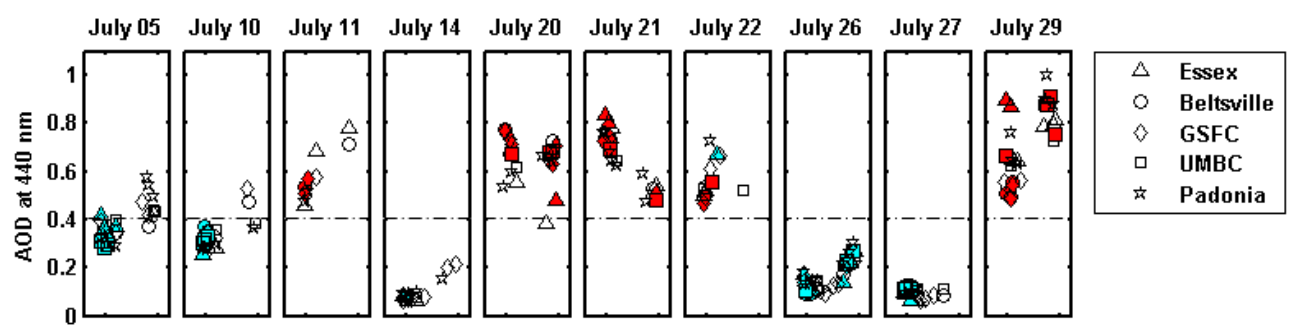

Figure 2. Aerosol optical depth (AOD) at $440 \mathrm{~nm}$ obtained from AERONET stations at Essex, Beltsville, Goddard Space Flight Center (GSFC), UMBC, and Padonia during all 10 days during DISCOVER-AQ in which there are synergistic measurements among UC-12, P3B, and the ground-based lidar at UMBC. Empty symbols represent available level 1.5 retrievals of size-related products, single-scattering albedo, and complex index of refraction. Cyan-filled symbols represent available level 2.0 retrievals of only size-related products. Red-filled symbols represent available level 2.0 retrievals size-related products, single-scattering albedo, and complex index of refraction. The $x$ axis of each window represents a day of AERONET measurement: sunrise to sunset.

During DISCOVER-AQ there were 10 days in which synergistic measurements were obtained from both aircraft and the UMBC ground-based lidar system (ALS-450): 5, 10, 11, $14,20,21,22,26,27$, and 29 July. Out of those 10 days we chose 5 for which retrievals of microphysical and optical properties from inversion of the hybrid lidar data set were obtained: 5, 20, 21, 22, and 29 July. The selection of those 5 days was mostly based on the aerosol loading observed at the stations of interest utilizing a similar requirement as that of AERONET level 2.0 retrievals of $\omega_{0}$ and $m$, i.e., $\tau_{440} \geq 0.4$. Figure 2 shows the AOD values at $440 \mathrm{~nm}$ obtained from the AERONET stations at Beltsville, Essex, Padonia, UMBC, and Goddard Space Flight Center (GSFC) during the aforementioned 10 days. In terms of AOD values, 5 July was a borderline case, but it was the only day when long-range transport of smoke was observed. The 11 July case met the $\tau_{440} \geq 0.4$ requirement but it was not included due to the presence of scattered clouds.

For each day, a number of "case studies" were selected, and for each of those a number of layers were selected in order to obtain microphysical retrievals through the inversion of the hybrid lidar data set. We chose layers where intensive parameters like Ångström exponent and lidar ratio were reasonably constant (based on the evaluation of the HSRL measurements). Table 1 lists all case studies as well as the layers considered for the inversion procedure. Coincidence times used for the comparisons of lidar results with in situ measurements and AERONET retrievals are also listed in Table 1. The lidar ratio varied by less than $8 \%$ in most cases, with the exception of case $\mathrm{H}$, in which the lidar ratio showed a $20 \%$ variation between the two layers analyzed for that particular case. Ångström exponents calculated from the backscatter coefficients at 532 and $1064 \mathrm{~nm}$ varied by less than $10 \%$ in most cases, except for case $\mathrm{G}$, in which a $32 \%$ variation was observed. It should be noted that both cases pertained to 22 July, which was a special case which will be discussed in more detail in Sect. 4.5.

\subsection{Hybrid multiwavelength lidar data set}

In order to obtain retrievals of the optical and microphysical properties of aerosols from a multiwavelength lidar system, a minimum set of backscatter and extinction coefficient measurements is required as demonstrated by Müller et al. (2001), Veselovskii et al. (2004), and Böckmann et al. (2005). As previously mentioned, most studies and efforts in characterizing the optical and microphysical properties of tropospheric aerosols through the inversion of multiwavelength lidar data have taken place in either Europe or Asia. Furthermore, most of those studies utilized Raman lidar systems that were specifically designed for multiwavelength measurements. These instruments were designed to emit and receive photons of all three wavelengths at the same time and through the same optical path, allowing for completely collocated measurements and therefore a more self-consistent $3 \beta+2 \alpha$ data set.

Compared to a few years ago, the availability of multiwavelength lidar systems has increased. Nevertheless, most of those systems are operated by EARLINET. Many lidar groups across the globe still operate instruments that are not capable of providing a complete $3 \beta+2 \alpha$ data set.

As an alternative to the $3 \beta+2 \alpha$ inversion methodology, some studies were carried out in which backscatter and extinction coefficients obtained from a Raman lidar were combined with optical depth measured by sunphotometer in order to derive the microphysical properties of aerosols (Pahlow et al., 2006; Tesche et al., 2008; Balis et al., 2010). However, the main challenge that comes to mind in this type of Raman lidar and AERONET data combination is temporal data collocation. Sunphotometers are fundamentally designed to be operated during daytime, while Raman lidars allow for good measurements mostly during nighttime. Alternatives in which Raman lidar data are not utilized have also been explored. Wagner et al. (2013) combined elastic backscatter lidar return signals at 355, 532, and $1064 \mathrm{~nm}$ and retrievals of volume concentration and column values of the volume-specific backscatter and extinction values obtained 
Table 1. List of cases analyzed. The letters in the first column represent the same cases as the ones depicted in Figs. 4 and 5. Time column lists the time span of the combined HSRL-1 and ALS-450 measurements. Layers were chosen in regions where the intensive properties such as color ratio and depolarization ratio did not vary much. P-3B in situ column lists the location of spirals which were used to compare lidar retrievals with in situ measurements, and $\mathrm{P} \Delta t$ lists the respective time gap between the overpass at UMBC and the spirals. The AERONET column lists the AERONET stations that were utilized for the retrievals comparison, including levels 1.5 and 2.0 , and A $\Delta t$ lists the respective time gap between the measurements at UMBC and the AERONET measurements. Figure 1 shows the AERONET and P-3B spirals' locations.

\begin{tabular}{|c|c|c|c|c|c|c|}
\hline & Day, time (UTC) & Layers & $\mathrm{P}-3 \mathrm{~B}$ in situ & $\mathrm{P} \Delta t(\min )$ & AERONET & $\mathrm{A} \Delta t(\min )$ \\
\hline (A) & 5 Jul, 09:41-09:59 & $\begin{array}{l}1.20-1.50 \mathrm{~km}(200 \mathrm{~m}) \\
1.65-2.00 \mathrm{~km}(350 \mathrm{~m}) \\
2.46-2.78 \mathrm{~km}(320 \mathrm{~m})\end{array}$ & Beltsville & +20 & $\begin{array}{l}\text { UMBC, GSFC, } \\
\text { Essex, Padonia }\end{array}$ & $\begin{array}{l}+90,+90 \\
+90,+90\end{array}$ \\
\hline (B) & $5 \mathrm{Jul}, 10: 52-11: 02$ & $\begin{array}{l}0.75-1.17 \mathrm{~km}(420 \mathrm{~m}) \\
1.56-1.70 \mathrm{~km}(140 \mathrm{~m}) \\
2.61-2.76 \mathrm{~km}(150 \mathrm{~m})\end{array}$ & Padonia & -30 & $\begin{array}{l}\text { UMBC, GSFC, } \\
\text { Essex, Padonia }\end{array}$ & $\begin{array}{l}+20,+20 \\
+20,+20\end{array}$ \\
\hline (C) & $5 \mathrm{Jul}, 11: 58-12: 10$ & $\begin{array}{l}0.84-1.08 \mathrm{~km}(240 \mathrm{~m}) \\
1.41-1.60 \mathrm{~km}(190 \mathrm{~m}) \\
2.19-2.34 \mathrm{~km}(150 \mathrm{~m})\end{array}$ & $\begin{array}{l}\text { Beltsville, } \\
\text { Essex }\end{array}$ & $\begin{array}{l}+15 \\
-15\end{array}$ & $\begin{array}{l}\text { UMBC, GSFC, } \\
\text { Essex, Padonia, } \\
\text { Beltsville }\end{array}$ & $\begin{array}{l} \pm 40, \pm 40 \\
\pm 40, \pm 40 \\
\quad \pm 40\end{array}$ \\
\hline (D) & 20 Jul, 19:54-20:17 & $\begin{array}{l}0.50-1.50 \mathrm{~km}(1 \mathrm{~km}) \\
1.50-2.50 \mathrm{~km}(1 \mathrm{~km})\end{array}$ & $\begin{array}{l}\text { Beltsville, } \\
\text { Padonia }\end{array}$ & $\begin{array}{l}-45 \\
-30\end{array}$ & $\begin{array}{l}\text { UMBC, Essex } \\
\text { Padonia }\end{array}$ & $\begin{array}{l}+90,+60 \\
\quad+5\end{array}$ \\
\hline (E) & 21 Jul, 14:47-14:54 & $\begin{array}{l}0.50-0.75 \mathrm{~km}(250 \mathrm{~m}) \\
1.00-1.50 \mathrm{~km}(500 \mathrm{~m}) \\
2.00-2.50 \mathrm{~km}(500 \mathrm{~m})\end{array}$ & $\begin{array}{l}\text { Beltsville, } \\
\text { Padonia }\end{array}$ & $\begin{array}{l}+40 \\
+60\end{array}$ & $\begin{array}{l}\text { UMBC, GSFC } \\
\text { Essex, Padonia }\end{array}$ & $\begin{array}{l}-40,-90 \\
-90,-30\end{array}$ \\
\hline$(\mathrm{F})$ & 21 Jul, 20:48-20:55 & $1.26-1.65 \mathrm{~km}(390 \mathrm{~m})$ & $\begin{array}{c}\text { Essex } \\
\text { Padonia }\end{array}$ & $+30,-40$ & $\begin{array}{l}\text { UMBC, GSFC, } \\
\text { Essex, Padonia, } \\
\text { Beltsville }\end{array}$ & $\begin{array}{c}+140,+140 \\
+140,-40 \\
+120\end{array}$ \\
\hline (G) & 22 Jul, 14:53-15:08 & $\begin{array}{l}1.00-1.50 \mathrm{~km}(500 \mathrm{~m}) \\
2.00-2.60 \mathrm{~km}(600 \mathrm{~m})\end{array}$ & $\begin{array}{l}\text { Beltsville, } \\
\text { Padonia }\end{array}$ & $\begin{array}{l}-60 \\
-30\end{array}$ & $\begin{array}{l}\text { UMBC, GSFC, } \\
\text { Essex }\end{array}$ & $\begin{array}{c}-120,+15 \\
-60\end{array}$ \\
\hline (H) & 22 Jul, 18:22-18:28 & $\begin{array}{l}0.50-1.00 \mathrm{~km}(500 \mathrm{~m}) \\
1.50-2.00 \mathrm{~km}(500 \mathrm{~m})\end{array}$ & $\begin{array}{l}\text { Beltsville, } \\
\text { Essex }\end{array}$ & $\begin{array}{c}+5 \\
-15\end{array}$ & UMBC & +90 \\
\hline (I) & 29 Jul, 15:18-15:29 & $\begin{array}{l}0.50-1.30 \mathrm{~km}(800 \mathrm{~m}) \\
1.50-1.86 \mathrm{~km}(360 \mathrm{~m})\end{array}$ & $\begin{array}{l}\text { Beltsville, } \\
\text { Padonia }\end{array}$ & $\begin{array}{l}+5 \\
+30\end{array}$ & $\begin{array}{l}\text { GSFC, Padonia, } \\
\text { Essex, Beltsville }\end{array}$ & $\begin{array}{c}(-5,-120),(-60,-120) \\
(-60,-120),-120\end{array}$ \\
\hline$(\mathrm{J})$ & 29 Jul, 20:12-20:18 & $0.50-2.00 \mathrm{~km}(1.5 \mathrm{~km})$ & $\begin{array}{l}\text { Beltsville, } \\
\text { Essex }\end{array}$ & $+5,-20$ & $\begin{array}{l}\text { UMBC, Essex, } \\
\text { Padonia }\end{array}$ & $\begin{array}{l}(+2,+60),+2 \\
(+15,+60)\end{array}$ \\
\hline$(\mathrm{K})$ & 29 Jul, 21:21-21:39 & $\begin{array}{l}0.72-1.30 \mathrm{~km}(580 \mathrm{~m}) \\
1.50-2.50 \mathrm{~km}(1 \mathrm{~km})\end{array}$ & Padonia & -60 & $\begin{array}{l}\text { UMBC, Essex } \\
\text { Padonia }\end{array}$ & $\begin{array}{c}(+5,-30),+60 \\
-30\end{array}$ \\
\hline
\end{tabular}

from AERONET as a priori assumptions in an optimization algorithm in order to obtain vertically resolved distributions of optical and microphysical properties of fine- and coarsemode particles. Lopatin et al. (2013) describe a new algorithm which also utilizes a combination of elastic lidar signals and AERONET sunphotometer retrievals in order to obtain vertical profiles of fine- and coarse-mode aerosol concentrations. The algorithm described by Lopatin et al. (2013) is very similar to the one utilized by Wagner et al. (2013), but, in addition to the retrievals of vertical profiles of aerosol concentrations, it also allows for retrievals of size distribution and complex refractive index for each aerosol mode.

The objective of this work was to explore the feasibility of applying the $3 \beta+2 \alpha$ inversion methodology to a hybrid multiwavelength lidar data set in order to expand the aerosol microphysical characterization efforts beyond what has been done so far.

During DISCOVER-AQ, the NASA UC-12 aircraft flew across the Baltimore-Washington DC region, with the HSRL-1 system (Hair et al., 2008) onboard obtaining profiles of extinction and backscatter coefficients at $532 \mathrm{~nm}$ utilizing the HSRL technique and profiles of backscatter coefficient at $1064 \mathrm{~nm}$ with the elastic technique. Measurements of the linear volume depolarization ratio at 532 and $1064 \mathrm{~nm}$ were also obtained simultaneously with the HSRL-1 system. Profiles of backscatter and extinction coefficients at $355 \mathrm{~nm}$ were obtained at the University of Maryland, Baltimore 


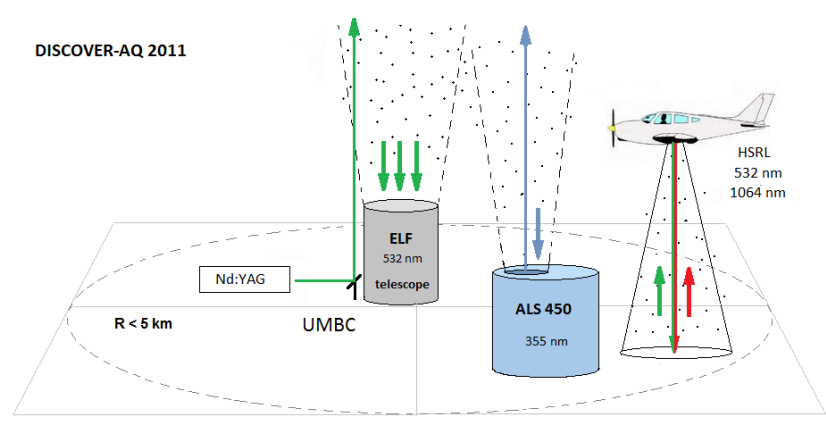

Figure 3. Setup of airborne and ground-based instruments at UMBC during DISCOVER-AQ 2011. A maximum radius of $5 \mathrm{~km}$ was considered to construct the hybrid multiwavelength lidar data set using HSRL and ALS-450 data.

County (UMBC), using a commercial ground-based elastic lidar (Leosphere, ALS-450).

In order to combine the dual-platform lidar measurements (e.g., airborne and ground based), a collocation radius of $5 \mathrm{~km}$ centered at the Department of Physics at UMBC $\left(39.25^{\circ} \mathrm{N},-76.71^{\circ} \mathrm{W}\right)$ was considered. Figure 3 depicts the setup. Within this radius it is assumed that the air mass is homogeneous enough that measurements from different instruments can be combined, and we examine this assumption.

The hybrid data set combines not only dual-platform measurements but also both elastic and HSRL techniques, which can be a challenging task.

The HSRL is a more robust technique when compared to the standard elastic lidar technique since it utilizes spectral delineation to separate the signal contribution due to aerosols and molecules, which allows for the determination of both backscatter and extinction coefficients independently. Elastic lidar systems, however, measure the total attenuated backscatter due to molecules and aerosols. For this type of system, the extinction coefficient is retrieved with the assumption of a constant extinction-to-backscatter ratio (i.e., lidar ratio). The lidar ratio, as an intensive property, varies with the type of aerosol. Therefore, the assumption of a constant lidar ratio throughout the whole column of the atmosphere can be problematic in cases when layers of different types of aerosols are present. In order to assess the feasibility of this new retrieval methodology, we tested the $5 \mathrm{~km}$ air mass homogeneity assumption as well as the constant lidar ratio assumption. This is discussed in the next section.

\subsubsection{Elastic lidar retrievals}

During this experiment, in addition to the airborne HSRL1 system and the ALS-450, another elastic lidar obtained measurements at $532 \mathrm{~nm}$ at UMBC's Elastic Lidar Facility (ELF).

The Leosphere ALS-450 is a commercial, eye-safe elastic lidar system that utilizes a frequency-tripled pulsed laser source Nd: YAG at $355 \mathrm{~nm}$ and repetition rate of $20 \mathrm{~Hz}$.
Measurements have a temporal and spatial resolution of $1 \mathrm{~min}$ and $15 \mathrm{~m}$, respectively. ELF utilizes a Q-switched Continuum Surelite II Nd: YAG operating at 1064 and $532 \mathrm{~nm}$ with $10 \mathrm{~Hz}$ repetition rate. ELF's signal is digitized with a $\mathrm{Li}$ cel TR20-160 photon counter and averaged for $1 \mathrm{~min}$, with a vertical resolution of $7.5 \mathrm{~m}$. More details on ELF system can be found elsewhere (Comer, 2003; Engel-Cox et al., 2006).

Both elastic systems utilize similar algorithms to retrieve the extinction coefficient from the total attenuated backscatter signal, which relies on closing the integrated extinction profile to AOD measurements obtained by a collocated AERONET sunphotometer. Having an elastic lidar at $532 \mathrm{~nm}$ at the same location as the ALS-450 enabled us to assess the two aforementioned assumptions (i.e., constant lidar ratio and the $5 \mathrm{~km}$ air mass homogeneity) at the same time by comparing the extinction coefficient profiles from ELF and from HSRL-1 using the same spatial subset proposed (i.e., $r<5 \mathrm{~km}$ ). Figure 4 shows the profiles comparison for all cases analyzed in this work (itemized in Table 1), which shows sufficient agreement. The error bars (shaded area) in the HSRL profile are the standard deviations of the profiles during an UMBC overpass, which usually lasted between 1 and $2 \mathrm{~min}$, resulting in an average of 5-10 profiles. The errors shown with the ELF profiles are the (1) standard deviation of 15 profiles, which represent a $15 \mathrm{~min}$ average centered at the UMBC overpass by the UC-12. The agreement observed between the HSRL and ELF profiles is a good indicator of the feasibility of combining dual-platform, dual-technique lidar data to perform the retrievals. For the cases at hand the aerosol intensive properties do not show much variation with altitude; therefore the assumption of a constant lidar ratio throughout the atmosphere is reasonable. The agreement between both profiles also indicates that the assumption of a homogeneous air mass within $5 \mathrm{~km}$ distance and/or $15 \mathrm{~min}$ temporal offset is reasonable as well. In Fig. 4 we also show the extinction profiles obtained from in situ measurements onboard the P-3B over the closest spiral sites from UMBC. Good agreement can be observed in most cases, which corroborates and also extends the air mass horizontal homogeneity assumption to larger distances (Padonia and Beltsville sites were about $22 \mathrm{~km}$ from UMBC and Essex about $10 \mathrm{~km}$ ). The discrepancies observed in other cases were mostly in isolated layers aloft where the homogeneity assumption fails.

The method utilized to obtain the aerosol extinction and backscatter profiles for both elastic lidar systems is an iterative algorithm that selects the optimum lidar ratio value by minimizing the residual between the AERONET AOD and the lidar AOD calculated from the integrated extinction coefficient profile. Some small differences in the algorithm utilized for ELF and the ALS-450 should be noted. ELF's algorithm utilizes AOD measurements of an entire day in the residue minimization process, thus resulting in a single value of the lidar ratio for that particular day. The algorithm utilized with the ALS-450 data set, however, was run on a case-by-case basis, obtaining a lidar ratio value for each 

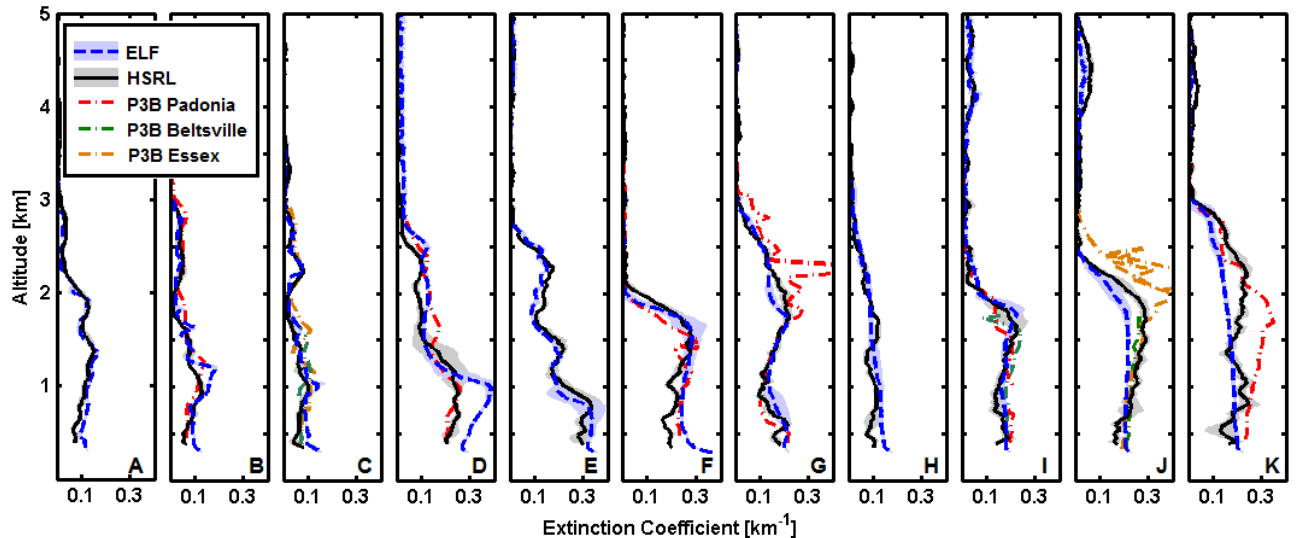

Figure 4. Extinction coefficient profiles obtained by HSRL (black solid lines) and by elastic lidar (blue dashed lines) at $532 \mathrm{~nm}$ for the cases listed in Table 1. Standard deviations of HSRL profiles are due to the profiles variation during a UMBC overpass $(\sim 1-2$ min, $\sim 8$ profiles $)$. Standard deviations of ELF profiles are due to profiles variation within $15 \mathrm{~min}$ centered at the overpass time. The dot-dashed lines represent in situ measurements obtained onboard the P3B over spiral sites that were closest to UMBC (red: Padonia; green: Beltsville; orange: Essex). The in situ profiles have been corrected to the ambient relative humidity.

case. Figure 5 shows the so-called $3 \beta+2 \alpha$ data set as well as the lidar ratio values at 355 and $532 \mathrm{~nm}$ obtained from both HSRL-1 and ALS-450. The error bars in the profiles at $355 \mathrm{~nm}$ were obtained by varying the system constant in the lidar equation by $\pm 5 \%$, and then averaging the lidar ratio values and the corresponding profiles. In a couple of cases, like seen in plots B and C from Fig. 5, the algorithm found a larger number of acceptable lidar ratio values, but it did not, however, translate to a large variation in the backscatter and extinction profiles.

\subsubsection{Lidar inversion algorithm for retrieval of microphysical and optical properties of aerosols}

The first inversion algorithm to retrieve aerosol microphysical properties from multiwavelength lidar data was originally described by Müller et al. (1998). Since then, many studies have been carried out showing that measurements of combined backscatter and extinction coefficients indeed allow for the retrieval of aerosol size distribution parameters with reasonable accuracy (Müller et al., 1999a, b, 2000; Veselovskii et al., 2002; Böckmann et al., 2005). The $3 \beta+2 \alpha$ data set is the minimum requirement for the retrieval of microphysical particle properties with the current inversion algorithm.

The inversion algorithm is to some extent based on nondescriptive methods, meaning that a priori information is kept at a minimum level. It utilizes a minimization concept, also known as the method of minimum distance (Tikhonov and Arsenin, 1977; Twomey, 1977), to find the solutions. In simple terms, this method selects solutions for which the residual between the solution of the forward problem and the backcalculated solution obtained from the inversion results is smaller than a pre-determined value $>0$. A smoothness constraint is also applied for the size distribution. Currently, the algorithm employs a modified minimum discrepancy method described by Veselovskii et al. (2002). The mathematical details of this method can be found in Müller et al. (1999a), Twomey (1977), and Ansmann and Müller (2005).

As the inversion problem must be discretized, one must utilize a so-called inversion window, which determines the size and complex index of refraction range in which the inversion will take place. The inversion window utilized in this work was $R_{\min }=0.01$ to $0.2 \mu \mathrm{m}$ with $0.01 \mu \mathrm{m}$ increments, $R_{\max }=0.5$ to $5 \mu \mathrm{m}$ with $0.5 \mu \mathrm{m}$ increments, $\operatorname{Re}[\mathrm{m}]=1.325$ to 1.5 with 0.025 increments, and $\operatorname{Im}[m]=0$ to 0.03 with 0.001 increments. $R_{\min }$ and $R_{\max }$ represent the values for the left- and rightmost edge of the size distribution, respectively. $\operatorname{Re}[m]$ and $\operatorname{Im}[m]$ are the real and imaginary parts of the complex index of refraction $(m)$, respectively. The algorithm assumes a wavelength-independent $m$.

As was explained in Sect. 3.1, a number of atmospheric layers were selected for each case study based on how the intensive parameters varied within those layers. In the case of elastic lidar systems, errors in the estimation of the lidar ratio value will propagate and add to errors in the retrievals of backscatter and extinction coefficients. For the majority of cases considered in this study (see Table 1), based on HSRL measurements at $532 \mathrm{~nm}$, the lidar ratio varied by less than $8 \%$ among the selected layers. Within each layer the variation observed in the process of spatial-temporal averaging of HSRL measurements (maximum of $5 \mathrm{~km}, 30 \mathrm{~min}$, respectively) was between 3 and $16 \%$. Given that the inversion algorithm has been shown to perform reasonably well with input errors of up to $20 \%$ (Böckmann et al., 2005; Veselovskii et al., 2002; Müller et al., 2005), the assumption of a constant lidar ratio for the cases at hand is acceptable. 

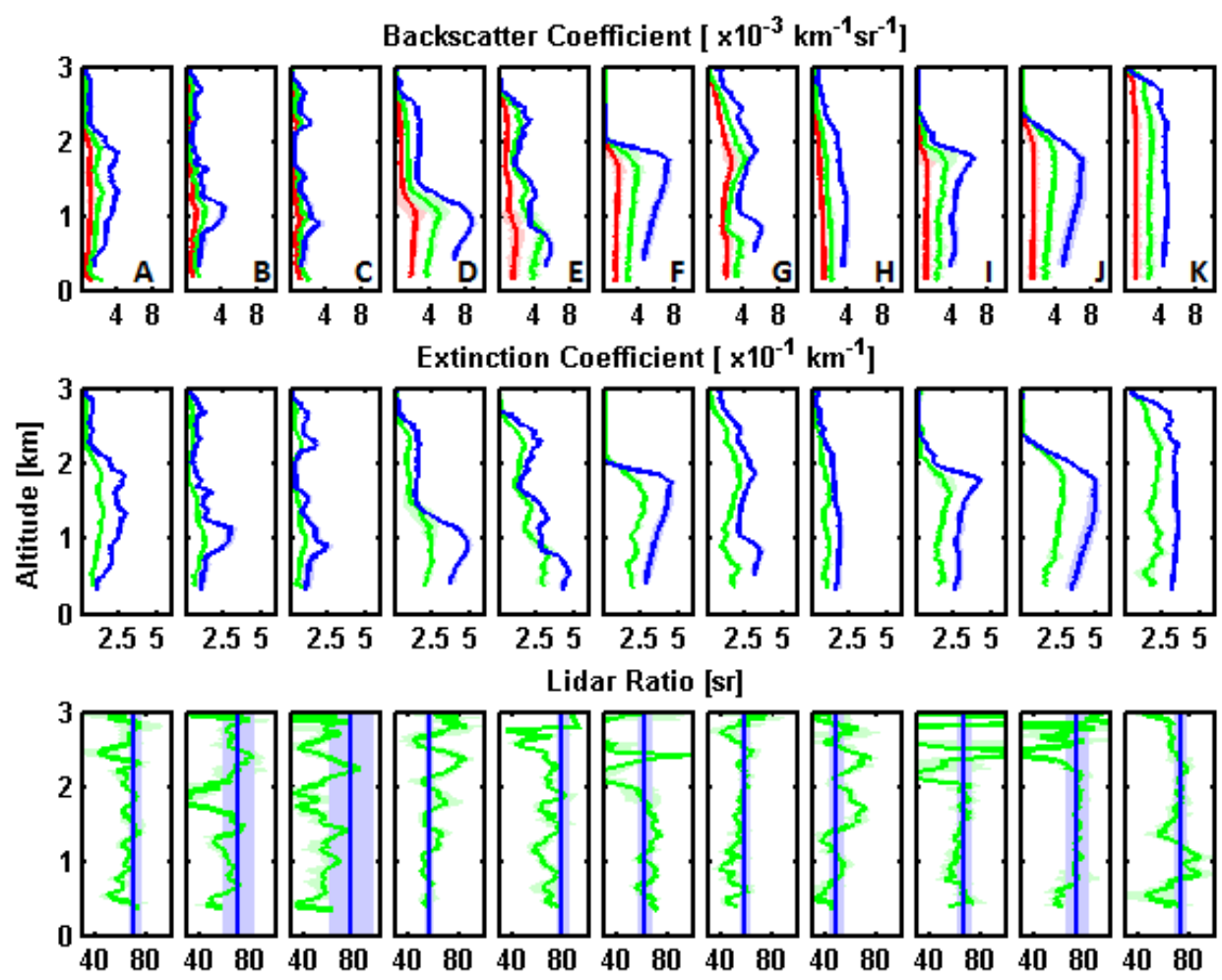

Figure 5. $3 \beta+2 \alpha$ and lidar ratio values obtained from the hybrid multiwavelength lidar data set. Green and red lines are airborne profiles at $532 \mathrm{~nm}$ (HSRL) and $1064 \mathrm{~nm}$ (elastic), respectively. Blue lines are from ground-based elastic lidar at $355 \mathrm{~nm}$. Letters correspond to each case analyzed, which are listed in detail in Table 1.

The inversion procedure was run seven times for each layer. In six of those runs, random errors of up to $15 \%$ were added to the $3 \beta+2 \alpha$ input set, while the remaining run did not have any noise added. This random error is included to account for errors in the measurements. Each inversion run generates a solution space which has to be further constrained in the post-processing step, which is the most time consuming part of the process. The constraints are different combinations of $R_{\min }, R_{\max }$, and other regularization parameters that are set manually, making it a very time-consuming task. For each of those 7 solution spaces generated, 5 to 10 post-processing constraints are chosen based on a number of criteria, including the number of final solutions, physically meaningful complex index of refraction values, and shape of size distribution. Therefore, for each layer analyzed, approximately 20 to 40 solutions are averaged for each variable: effective radius ( $R_{\text {eff }}$ ), volume concentration, surfacearea concentration, real and imaginary parts of $m$, and singlescattering albedo $\left(\omega_{0}\right)$.

Regarding error analysis, in this study we only report the statistical error for each retrieved parameter, which is calculated as the standard deviation of the averaged solutions (Ansmann and Müller, 2005; Veselovskii et al., 2002). The use of a constant and/or inaccurate lidar ratio value for the retrievals of extinction and backscatter coefficients from an elastic lidar can introduce systematic errors into the microphysical retrievals. Although a careful analysis and validation of the elastic lidar retrievals were performed, systematic errors were not taken into account in this study. A sensitivity study on the effects of systematic errors in the lidar retrievals of microphysical parameters has been performed and reported by Pérez-Ramírez et al. (2013).

\section{Results}

\subsection{Overview}

Figure 6 shows the individual results obtained for effective radius, volume and surface-area concentrations, singlescattering albedo, and complex index of refraction from inversion of the hybrid multiwavelength lidar data set $(3 \beta+$ $2 \alpha$ ), from AERONET inversions, and from in situ measurements obtained by the P-3B aircraft.

Table 2 summarizes the averages over all layers analyzed in this study for each aerosol parameter. We present different averaging subsets for AERONET retrievals, since both level 1.5 and level 2.0 data were utilized in the comparison. Subsets 1 and 2 contain the AERONET data described in Table 1, which are level 1.5 and level 2.0, respectively. Subset 3 contains all level 2.0 data from 1 to 31 July 2011. For the cases 

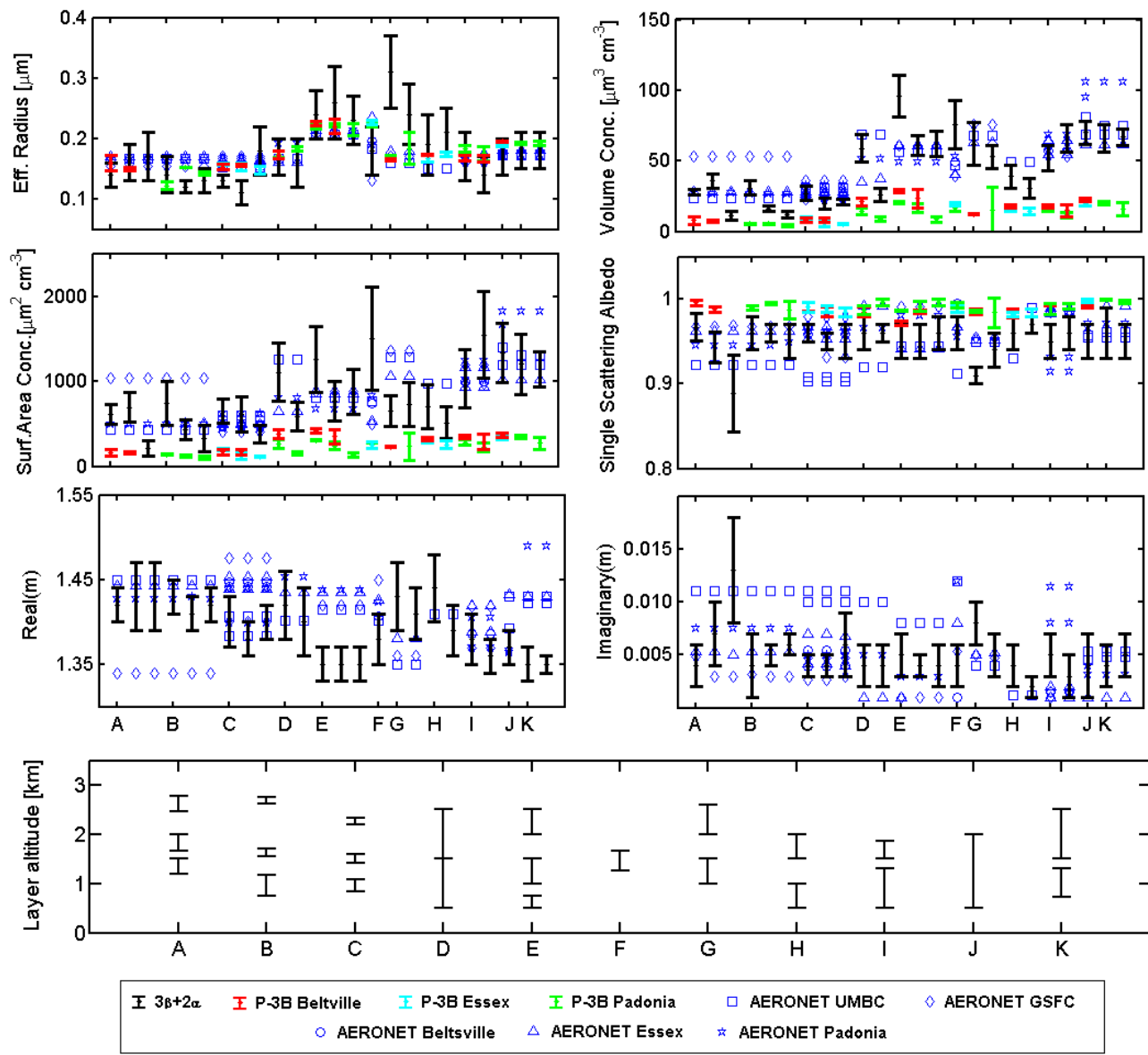

Figure 6. Results of effective radius, volume and surface-area concentrations, single-scattering albedo, and complex index of refraction obtained from inversion of the hybrid multiwavelength lidar data set $(3 \beta+2 \alpha)$, from AERONET inversions, and from in situ measurements obtained by the P-3B aircraft (under dry conditions).

utilized in this study, it should be noted that subset 2 is part of subset 1 since there were no differences in values between level 1.5 and level 2.0. The numbers between parentheses in columns $R_{\text {eff }}$ and $\omega_{0}$ for the AERONET data represent the number of data points in each subset for each station.

As can be seen in Fig. 6 and Table 2, the lidar retrievals, in general, showed better agreement with AERONET retrievals than with the in situ measurements. The results are discussed in more detail in the following sections.

The average single-scattering albedo value obtained from the lidar retrievals was $\omega_{0}=0.95 \pm 0.02$, which agrees with the values reported in the literature for the BaltimoreWashington DC region at this particular time of the year. Dubovik et al. (2002) analyzed 8 years of worldwide AERONET retrievals and reported an average value of $\omega_{0}(550 \mathrm{~nm}) \sim 0.97$ for the GSFC station between June and September.

The $m$ values obtained from our lidar retrievals also agree well with other values reported in the literature. Combining simultaneous in situ size distribution profile measurements obtained onboard an aircraft with lidar aerosol backscatter and optical depth profiles, Redemann et al. (2000) obtained profiles of wavelength-independent $m$ for two case studies during TARFOX, resulting in average values of $\operatorname{Re}[\mathrm{m}]=$ $1.41 \pm 0.06$ and $\operatorname{Im}[m]=0.004 \pm 0.003$. Dubovik et al. (2002) reported $\operatorname{Re}[m]=1.40 \pm 0.01$ at GSFC (averaged over all wavelengths) from AERONET retrievals. Both results are consistent with those obtained from the lidar retrievals.

Nighttime optical and microphysical retrievals between 1 and $3 \mathrm{~km}$ altitude were also obtained from a multiwavelength Raman lidar for two cases during DISCOVER-AQ 2011 (21 and 22 July) (Veselovskii et al., 2013). Those retrievals were obtained with a recently developed algorithm in which $3 \beta+1 \alpha$ data are utilized instead (Veselovskii et al., 2012a). The measurements from Veselovskii et al. (2013) were not coincident with those obtained in this study (nighttime vs. daytime) and therefore comparison of the results is not presented in this contribution. 
Table 2. Average of results obtained from lidar retrievals (i.e., $3 \beta+2 \alpha$ ) and in situ measurements from P-3B flights, and AERONET retrievals of effective radius $\left(R_{\text {eff }}\right)$, volume and surface-area concentrations, and single-scattering albedo. Real and imaginary parts of the complex index of refraction were compared to AERONET only. Maximum aerosol layer height (AHL) was assumed to be $1.5 \mathrm{~km}$ in order to convert AERONET volume and surface-area concentrations from per unit area to per unit volume. Mean values from AERONET are presented for three different averaging subsets. Number of data points for each subset is presented between parentheses for size- and optical-related parameters.

\begin{tabular}{lcccccc}
\hline & $\begin{array}{c}R_{\text {eff }} \\
{[\mu \mathrm{m}]}\end{array}$ & $\begin{array}{c}\text { Vol. conc. } \\
{\left[\mu \mathrm{m}^{3} \mathrm{~cm}^{-3}\right]}\end{array}$ & $\begin{array}{c}\text { S-area conc. } \\
{\left[\mu \mathrm{m}^{2} \mathrm{~cm}^{-3}\right]}\end{array}$ & $\omega_{0}$ & $\operatorname{Re}(m)$ & $\operatorname{Im}(m)$ \\
\hline $3 \beta+2 \alpha$ & $0.18 \pm 0.05$ & $45 \pm 23$ & $821 \pm 369$ & $0.95 \pm 0.02$ & $1.39 \pm 0.03$ & $0.005 \pm 0.002$ \\
P-3B Beltsville & $0.13 \pm 0.02$ & $10 \pm 5$ & $224 \pm 74$ & $0.99 \pm 0.01$ & N/A & N/A \\
P-3B Essex & $0.13 \pm 0.02$ & $8 \pm 4$ & $181 \pm 65$ & $0.99 \pm 0.01$ & N/A & N/A \\
P-3B Padonia & $0.14 \pm 0.02$ & $8 \pm 3$ & $178 \pm 57$ & $0.99 \pm 0.01$ & N/A & N/A \\
AERO UMBC $^{\mathrm{a}}$ & $0.17 \pm 0.02(11)$ & $54 \pm 20$ & $963 \pm 350$ & $0.94 \pm 0.03(11)$ & $1.41 \pm 0.03$ & $0.007 \pm 0.004$ \\
AERO UMBC $^{\mathrm{b}}$ & $0.17 \pm 0.01(8)$ & $51 \pm 21$ & $925 \pm 377$ & $0.94 \pm 0.02(5)$ & $1.40 \pm 0.03$ & $0.007 \pm 0.003$ \\
AERO UMBC $^{\mathrm{c}}$ & $0.16 \pm 0.02(51)$ & $31 \pm 19$ & $580 \pm 311$ & $0.94 \pm 0.02(15)$ & $1.41 \pm 0.03$ & $0.008 \pm 0.003$ \\
AERO GSFC $^{\mathrm{a}}$ & $0.18 \pm 0.03(10)$ & $51 \pm 15$ & $871 \pm 297$ & $0.98 \pm 0.01(10)$ & $1.40 \pm 0.04$ & $0.003 \pm 0.002$ \\
AERO GSFC $^{\mathrm{b}}$ & $0.19 \pm 0.03(4)$ & $47 \pm 19$ & $747 \pm 364$ & $0.98 \pm 0.01(3)$ & $1.41 \pm 0.04$ & $0.003 \pm 0.002$ \\
AERO GSFC $^{\mathrm{c}}$ & $0.16 \pm 0.03(53)$ & $33 \pm 21$ & $603 \pm 333$ & $0.98 \pm 0.01(20)$ & $1.40 \pm 0.03$ & $0.003 \pm 0.002$ \\
AERO Essex $^{\mathrm{a}}$ & $0.18 \pm 0.02(10)$ & $47 \pm 16$ & $783 \pm 259$ & $0.97 \pm 0.02(10)$ & $1.43 \pm 0.02$ & $0.004 \pm 0.003$ \\
AERO Essex $^{\mathrm{b}}$ & $0.18 \pm 0.02(4)$ & $45 \pm 21$ & $761 \pm 323$ & $0.96 \pm 0.03(2)$ & $1.41 \pm 0.03$ & $0.005 \pm 0.005$ \\
AERO Essex $^{\mathrm{c}}$ & $0.16 \pm 0.03(45)$ & $27 \pm 21$ & $471 \pm 345$ & $0.97 \pm 0.02(13)$ & $1.42 \pm 0.04$ & $0.004 \pm 0.002$ \\
AERO Beltsville $^{\mathrm{a}}$ & $0.17 \pm 0.02(4)$ & $40 \pm 13$ & $673 \pm 250$ & $0.98 \pm 0.02(4)$ & $1.42 \pm 0.03$ & $0.003 \pm 0.002$ \\
AERO Beltsville $^{\mathrm{b}}$ & $0.17 \pm 0.01(2)$ & $40 \pm 20$ & $732 \pm 375$ & $\mathrm{~N} / \mathrm{A}$ & $\mathrm{N} / \mathrm{A}$ & $\mathrm{N} / \mathrm{A}$ \\
AERO Beltsville $^{\mathrm{c}}$ & $0.16 \pm 0.02(70)$ & $27 \pm 21$ & $487 \pm 315$ & $0.97 \pm 0.02(10)$ & $1.40 \pm 0.03$ & $0.003 \pm 0.002$ \\
AERO Padonia $^{\mathrm{a}}$ & $0.18 \pm 0.02(10)$ & $57 \pm 27$ & $968 \pm 479$ & $0.95 \pm 0.02(10)$ & $1.41 \pm 0.03$ & $0.006 \pm 0.003$ \\
\hline
\end{tabular}

${ }^{\mathrm{a}}$ Level 1.5: data subset used to compare with lidar retrievals listed in Table 1. ${ }^{\mathrm{b}}$ Level 2.0: data subset used to compare with lidar retrievals listed in Table 1 (less data points). ${ }^{c}$ Level 2.0: average of July 2011 data.

\subsection{Comparison to in situ measurements}

Due to air traffic limitations, the P-3B did not fly spirals over UMBC. Therefore, the retrievals of effective radius, volume and surface concentrations, and single-scattering albedo obtained from the inversion of the hybrid lidar data set at UMBC were compared to the in situ measurements obtained over the closest spiral sites: Beltsville, Essex, and Padonia (Fig. 1).

It should be noted that the in situ data are mostly representative of dry instead of ambient conditions. Corrections with respect to hygroscopic growth effects were not applied in this study, and this limitation is discussed in the following subsections.

\subsubsection{Size parameters}

A systematic bias was observed between the lidar retrievals and the in situ measurements of volume and surface-area concentrations. Compared to lidar retrievals, the P-3B measurements show an average underestimation of about 81 and $77 \%$ for volume and surface-area concentration, respectively. The effective radius shows a lower bias of $21 \%$. The shape of the profiles, however, are in good agreement.
It should be noted that size distribution data from the UHSAS are typically reported referenced to calibrations using polystyrene latex sphere (PSL) particles with a refractive index of 1.59. Because the UHSAS employs an optical detection scheme, particle sizing (and thus the derived surface area, volume, and effective radius) is sensitive to changes in the real part of the particle refractive index. In order to better compare to realistic particle compositions, which most likely consisted of mixtures of organic compounds and ammonium sulfate (AS), data were corrected using monodisperse AS calibration aerosol (refractive index of 1.53). The resulting correction factors varied from flight to flight due to variations in aerosol composition and had average values of $1.44,1.22$, and 1.28 for volume, surface area, and effective radius, respectively. Note that this correction only applies to in situ size distributions with dry RH (less than $40 \%$ ).

After applying the aforementioned correction factors to the UHSAS measurements, we observed an overall improvement on the comparisons between the lidar retrievals and the UHSAS measurements. Volume and surface-area concentrations from the UHSAS measurements still show underestimation when compared to the lidar retrievals, but the differences are reduced to $71 \%$. Effective radius, on the other hand, improved to an average of $-3 \%$, showing a slight overestimation with respect to the lidar retrievals. The in situ 
size parameters displayed in Fig. 6 represent the corrected data.

The differences observed in volume and surface-area concentrations between the lidar retrievals and the in situ measurements were first thought to be related to possible inlet issues in the P-3B aircraft. Ziemba et al. (2013), however, concluded that particle loss due to the aerosol inlet was likely negligible after obtaining a good correlation $\left(r^{2}=0.88\right)$ between in situ extinction coefficient measurements from the P$3 \mathrm{~B}$ at $532 \mathrm{~nm}$ and those obtained from HSRL also at $532 \mathrm{~nm}$. This improved correlation (from $r^{2}=0.81$ ) was obtained after the optical measurements obtained from the P-3B were corrected for ambient RH using the measurements of hygroscopicity also obtained onboard. With this comparison Ziemba et al. (2013) found a liquid-water contribution to ambient extinction of up to $43 \%$.

After ruling out possible aircraft inlet issues, the most likely factor contributing to this difference is related to aerosol hydration processes. Condensation and evaporation from the particles' surfaces during sampling are known to occur (Biswas et al., 1987; Leaitch and Isaac, 1991), which dries the aerosol during probing. The two nephelometers onboard the $\mathrm{P}-3 \mathrm{~B}$ were utilized to calculate the changes in aerosol scattering due to hygroscopic growth, commonly expressed as $f(\mathrm{RH})$. The hygroscopic growth, however, is determined by the relative increase in the diameter of the aerosol particles due to water uptake (Winkler, 1988), commonly expressed by the grow factor $g(\mathrm{RH})$, which was not measured during DISCOVER-AQ. Therefore, corrections to the size distributions obtained by both UHSAS and LAS instruments with respect to water uptake were not performed.

The size parameters obtained from the lidar retrievals are representative of particles at ambient humidity conditions and the ones obtained from the UHSAS on board P-3B are representative of particles in their dry state. The ratio of volume concentration can then be considered a first approximation for $\bar{g}^{3}(\mathrm{RH})$, and the ratio of surface-area concentrations an approximation for $f(\mathrm{RH}), \bar{g}(\mathrm{RH})$ describes an average of effective growth factor for the entire range of particle diameters. The ratio obtained in this study for the growth factor was $\bar{g}=1.75 \pm 0.17$. The values for $\bar{g}(\mathrm{RH})$ reported in the literature for ammonium sulfate at 355 and $532 \mathrm{~nm}$ fall within the range $1.44-1.46$ at $\mathrm{RH}=80 \%$ and $1.69-1.77$ at $\mathrm{RH}=90 \%$ (Michel Flores et al., 2012; Gysel et al., 2002; Dinar et al., 2008; Sjogren et al., 2007). In terms of $f(\mathrm{RH})$, the value obtained from the ratio between lidar and UHSAS surfacearea concentration values was $f(\mathrm{RH})=2.16 \pm 0.34$. Average values of $f(\mathrm{RH})$ between 11:00 and 13:00 (EDT) during DISCOVER-AQ (below $1 \mathrm{~km}$ altitude) ranged between 1.28 and 1.91 (Ziemba et al., 2013).

We emphasize the fact that the value obtained for $\bar{g}(\mathrm{RH})$ in this study can only be considered as a rough estimate of the hygroscopic growth factor. Also, the difference between the $f(\mathrm{RH})$ value obtained from this comparison and the values obtained by Ziemba et al. (2013) was marginal within 1 to 2 standard deviations. Aerosol hydration processes were clearly a major factor that caused difference observed between the size parameters retrieved from the lidar data and from the airborne in situ measurements. However it remains inconclusive whether the difference was solely due to hydration processes. This matter will be subject to further investigations in future studies.

\subsubsection{Single-scattering albedo}

Measurements obtained by the P-3B show a systematic overestimation of the single-scattering albedo compared to the lidar-retrieved values. The average value is $\omega_{0}=0.99 \pm 0.01$ for all spiral sites. Another aircraft experiment conducted in the Mid-Atlantic region of the United States in July 1993, SCAR-A (Remer et al., 1997), reported a best-estimate value similar to those obtained by the P-3B, $\omega_{0}(450 \mathrm{~nm}) \sim 0.98-$ 0.99 .

There are still many uncertainties with regard to how lightabsorbing aerosols affect our climate. The main uncertainties are related to their mixing state with other particles, as well as to how light-absorbing particles respond to changes in ambient RH (Redemann et al., 2001; Haywood and Ramaswamy, 1998; Andreae, 2001).

Therefore, it is clear that caution is needed when comparing single-scattering albedo retrievals obtained from remote sensors such as lidars or sun-sky radiometers (AERONET), which measure scattering from aerosols at ambient RH, with measurements from in situ samplers, which measure particles under drier conditions, due to either inlet effects or as a result of intentionally drying the aerosols before sampling them. RH was measured onboard the P-3B and the average $\mathrm{RH}$ values, considering all cases and layers analyzed in this work, were $\mathrm{RH}=70 \% \pm 10 \%$ in Beltsville, $\mathrm{RH}=70 \% \pm 8 \%$ in Essex, and $\mathrm{RH}=71 \% \pm 8 \%$ in Padonia. When comparing our lidar retrievals of $\omega_{0}$ to the in situ measurements obtained onboard P-3B, no corrections with respect to humidification factors were performed, which might explain the larger difference observed.

\subsection{Comparison to AERONET retrievals}

As previously mentioned, AERONET releases its aerosol products as level 1.5 and level 2.0 (Dubovik et al., 2000; Holben et al., 2006). Due to the large number of criteria utilized to screen the data, there are few level 2 data during the period analyzed in this study. Therefore, for our comparison studies, we utilized both level 1.5 and level 2.0. It should be noted that size-related parameters (i.e., effective radius and volume and surface-area concentrations) usually contain more level 2 data than the optical-related parameters (i.e., singlescattering albedo and complex index of refraction) due to the additional requirement $\tau_{440} \geq 0.4$ for the latter. 
Table 3. July mean values of effective radius $R_{\text {eff }}$ for different aerosol loadings and different quality levels for all AERONET/DRAGON stations considered in this study.

\begin{tabular}{|c|c|c|c|c|c|c|}
\hline & \multicolumn{6}{|c|}{$R_{\text {eff }}$} \\
\hline & \multicolumn{2}{|c|}{$0 \leq \tau_{440} \leq 0.2$} & \multicolumn{2}{|c|}{$0.2 \leq \tau_{440} \leq 0.4$} & \multicolumn{2}{|c|}{$\tau_{440} \geq 0.4$} \\
\hline & Level 1.5 & Level 2.0 & Level 1.5 & Level 2.0 & Level 1.5 & Level 2.0 \\
\hline Beltsville & $0.14 \pm 0.01(27)$ & $0.14 \pm 0.01(17)$ & $0.15 \pm 0.01(21)$ & $0.16 \pm 0.01(10)$ & $0.18 \pm 0.02(22)$ & $0.19 \pm 0.02(10)$ \\
\hline Essex & $0.15 \pm 0.02(38)$ & $0.15 \pm 0.02(20)$ & $0.16 \pm 0.02(28)$ & $0.16 \pm 0.01(12)$ & $0.19 \pm 0.02(36)$ & $0.18 \pm 0.03$ \\
\hline GSFC & $0.14 \pm 0.01$ & $0.14 \pm 0.01(25)$ & $0.15 \pm 0.01(29)$ & $0.15 \pm 0.01(10)$ & $0.18 \pm 0.03$ & $0.18 \pm 0.03(20)$ \\
\hline UMBC & $0.14 \pm 0.01$ & $0.14 \pm 0.01(23)$ & $0.15 \pm 0.01$ & $0.15 \pm 0.01(21)$ & $0.17 \pm 0.02(32)$ & $0.18 \pm 0.02(15)$ \\
\hline Padonia & $0.14 \pm 0.02(41)$ & N/A & $0.15 \pm 0.02(50)$ & N/A & $0.18 \pm 0.02(37)$ & N/A \\
\hline
\end{tabular}

DRAGON sunphotometers were pre- and post-calibrated for DISCOVER-AQ 2011, and the data undergo the same quality control and quality assurance as the data obtained by the regular AERONET instruments.

Level 1.5 retrievals are only cloud screened, and not quality assured like level 2.0 retrievals. In order to use level 1.5 retrievals in the intercomparison with in situ measurements and lidar retrievals, we first compared their range of values to those found in the level 2.0 retrievals. We used the statistics obtained from the July 2011 data to judge whether level 1.5 retrievals could be used in the comparisons.

Table 3 shows the difference in mean effective radius values for the month of July for each AERONET/DRAGON station considered in this study for three distinct ranges of aerosol optical depth at $440 \mathrm{~nm}$. The differences for effective radius from level 1.5 and level 2.0 retrievals never exceed $0.01 \mu \mathrm{m}$, except for Padonia station, which does not have level 2.0 data. However, compared to the other stations, the level 1.5 effective radius retrieved for Padonia is also within $0.01 \mu \mathrm{m}$ to both level 1.5 and level 2.0 retrievals obtained at the other stations.

Table 4 shows the same comparison as Table 3 but for single-scattering albedo. Here we can clearly see the negative bias in the level $1.5 \omega_{0}$ values obtained for $\tau_{440} \leq 0.4$ for UMBC and Padonia. Level 2.0 data at UMBC are about 0.03 lower compared to the data from Beltsville, Essex, and GSFC. Padonia level 1.5 average retrieval results for $\tau_{440} \geq$ 0.4 agree well with both level 1.5 and 2.0 retrieval results from Beltsville, Essex, and GSFC.

Based on the results presented in Tables 3 and 4, it was concluded that level 1.5 retrievals of size parameters, singlescattering albedo, and complex index of refraction could be used for the intercomparison, as the level 1.5 values obtained for $\tau 440 \geq 0.4$ were comparable to the level 2.0 values. However, retrievals of single-scattering albedo and complex index of refraction obtained at UMBC should be taken with caution as they show a negative bias with respect to the other stations.

\subsubsection{Size parameters}

The AERONET volume particle size distributions are retrieved in 22 logarithmically equidistant bins in the radius range size of $0.05 \mu \mathrm{m} \leq r \leq 15 \mu \mathrm{m}$. The ranges of retrievable real and imaginary parts of the $m$ are $1.33 \leq \operatorname{Re}[m] \leq 1.6$ and $0.0005 \leq \operatorname{Im}[m] \leq 0.5$, respectively. Details on the algorithms can be found in Dubovik and King (2000) and Dubovik et al. (2000).

Only the fine-mode retrievals were considered in the comparison of size parameters. Also, as the retrievals are obtained for the total column of the atmosphere, the volume particle size distribution is retrieved per unit area $\left(\mu \mathrm{m}^{3} \mathrm{~cm}^{-2}\right)$ instead of per unit volume $\left(\mu \mathrm{m}^{3} \mathrm{~cm}^{-3}\right)$. In order to compare AERONET to lidar retrievals, it is necessary to introduce an "aerosol layer height" (ALH) that represents the altitude below which most aerosol particles are confined. For this study, based on the lidar data, we chose ALH $=1.5 \mathrm{~km}$. Here it is important to emphasize that the comparison of lidar retrievals of size parameters to AERONET retrievals was not meant as a validation tool for either technique, since one simply cannot compare a total column retrieval to a retrieval that was performed for individual layers and expect a $1: 1$ agreement. Instead, this comparison serves as a way of checking whether a reasonable agreement could be observed between AERONET and lidar retrievals by using a reasonable ALH to convert a per unit area to a per unit volume quantity.

Figure 6 shows that reasonable agreement is observed in many cases. In this figure the values obtained from the lidar retrievals for each layer (i.e., values found between $x$ axis marks A and K) are representative of retrievals at different altitudes. AERONET retrievals, on the other hand, being a total column retrieval, are repeated (between $x$ axis marks) so that all layers analyzed for a particular day and time are compared to the same AERONET "volume-converted" value.

\subsubsection{Single-scattering albedo and complex index of refraction}

AERONET retrievals of $\omega_{0}$ and $m$ are reported at wavelengths $440,675,870$, and $1020 \mathrm{~nm}$. A third-order 
Table 4. July mean values of single-scattering albedo $\omega_{0}$ for different aerosol loadings and different quality levels for all AERONET/DRAGON stations considered in this study.

\begin{tabular}{lcccc}
\hline & \multicolumn{4}{c}{$\omega_{0}$ at $532 \mathrm{~nm}$} \\
\cline { 2 - 5 } & $0 \leq \tau_{440} \leq 0.2$ & $0.2 \leq \tau_{440} \leq 0.4$ & \multicolumn{2}{c}{$\tau_{440} \geq 0.4$} \\
\cline { 2 - 5 } & Level 1.5 & Level 1.5 & Level 1.5 & Level 2.0 \\
\hline Beltsville & $0.93 \pm 0.05(27)$ & $0.96 \pm 0.03(21)$ & $0.97 \pm 0.02(22)$ & $0.97 \pm 0.02(10)$ \\
Essex & $0.96 \pm 0.03(38)$ & $0.97 \pm 0.02(28)$ & $0.97 \pm 0.05(36)$ & $0.97 \pm 0.02(13)$ \\
GSFC & $0.96 \pm 0.03(49)$ & $0.96 \pm 0.02(29)$ & $0.98 \pm 0.01(43)$ & $0.98 \pm 0.01(20)$ \\
UMBC & $0.84 \pm 0.07(37)$ & $0.90 \pm 0.04(35)$ & $0.94 \pm 0.03(32)$ & $0.94 \pm 0.02(15)$ \\
Padonia & $0.84 \pm 0.05(41)$ & $0.92 \pm 0.06(50)$ & $0.97 \pm 0.02(37)$ & N/A \\
\hline
\end{tabular}

polynomial regression was utilized to interpolate the AERONET retrievals at $532 \mathrm{~nm}$ in order to compare them to the lidar retrievals also at $532 \mathrm{~nm}$.

The lidar retrieval algorithm assumes a wavelengthindependent refractive index. The combination of refractive index and the retrieved size distributions allows for the calculation of scattering and absorption coefficients at the lidar wavelengths $(355,532,1064 \mathrm{~nm})$, therefore also allowing for computation of single-scattering albedo at those wavelengths despite the assumption of a wavelength-independent refractive index. Since $532 \mathrm{~nm}$ is the mean wavelength utilized in the retrievals and, in this particular case, the only channel in which backscatter and extinction coefficients are independently measured (with HSRL technique), it was decided that only the single-scattering albedo retrieved at $532 \mathrm{~nm}$ would be utilized in the comparisons.

We also compare the refractive index to the AERONET retrievals interpolated at $532 \mathrm{~nm}$. However, as AERONET provides wavelength-dependent retrievals of $m$ (i.e., at 440, 675, $870,1022 \mathrm{~nm}$ ), we were able to look into the differences between the values of both real and imaginary parts of $m$ interpolated at $532 \mathrm{~nm}$ and the values obtained from the average of the wavelength-dependent $m$ across the four wavelengths. The 90th percentiles ( $p 90)$ of those differences were calculated using all the available AERONET retrievals obtained during the month of July 2011 at the UMBC, GSFC, Padonia, Essex, and Beltsville stations. Regarding the real part of $m$, the differences were less than 0.03 for all stations. For the imaginary part the $p 90$ values were all below 0.0038 . These differences may be interpreted as an additional error in the comparison of refractive index for using the AERONET retrievals at $532 \mathrm{~nm}$ instead of the average values calculated over all wavelengths.

The single-scattering albedo values obtained from the AERONET stations fall in between the retrievals obtained from lidar and those obtained from in situ measurements. The values agree with the lidar retrievals within 1 standard deviation. Schafer et al. (2014) also performed single-scattering albedo comparisons between AERONET and in situ measurements during DISCOVER-AQ 2011. They reported that AERONET level 2.0 retrievals of single-scattering albedo (interpolated at $550 \mathrm{~nm})$ at high aerosol loadings $\left(\tau_{440} \geq 0.4\right)$ were on average 0.011 lower than the in situ measurements. The results from this study with respect to single-scattering albedo are consistent with those of Schafer et al. (2014).

On average, the lidar retrievals compared better with the AERONET retrievals obtained at Essex station for both subsets 1 and 2 . The average results presented for different AERONET subsets in Table 2 show differences between the mean values obtained for the whole month and the mean values obtained over the 5 days analyzed in this study $(5,20$, 21, 22, and 29 July). For instance, we observe larger differences among parameters related to size distribution than among optical parameters when comparing subsets 1,2 , and 3 . This difference can be expected, as the 5 days chosen for our analysis experienced the highest aerosol loading when compared to the rest of the month. For effective radius we observe an increase in bias between the lidar and AERONET retrievals that ranges between $[-6 \%,+6 \%]$ for subsets 1 and 2 and $-11 \%$ for subset 3 . Bias in volume and surfacearea concentrations shifted from $[-18 \%,+27 \%]$ to $[-43 \%$, $-27 \%]$. As for the optical parameters the changes were less significant, single-scattering albedo went from $[-1.1 \%$, $+3.2 \%]$ to $[-1 \%,+3.2 \%], \operatorname{Re}[\mathrm{m}]$ from $[+0.7 \%,+2.9 \%]$ to $[+0.7 \%,+2.2 \%]$, and $\operatorname{Im}[\mathrm{m}]$ from $[-40 \%,+40 \%]$ to $[-40 \%,+60 \%]$. The larger difference in the latter is related to the retrievals at UMBC, which throughout the campaign displayed a systematic bias towards larger values in the imaginary part of the $m$, even for level 2.0 retrievals. The origin of this bias is still unknown, but it has been speculated that calibration issues could have been at fault.

The lidar retrievals of volume and surface-area concentrations and real part of $m$ agree marginally better with AERONET level 2.0 retrievals (subset 2) than with level 1.5 retrievals (subset 1). For most parameters, as can be seen in Table 2, the differences between AERONET results averaged over subsets 1 and 2 were very small.

\subsection{July: unusual single-scattering albedo case}

During the first week of July, wildfires were observed in North and South Carolina in the United States, as well as 


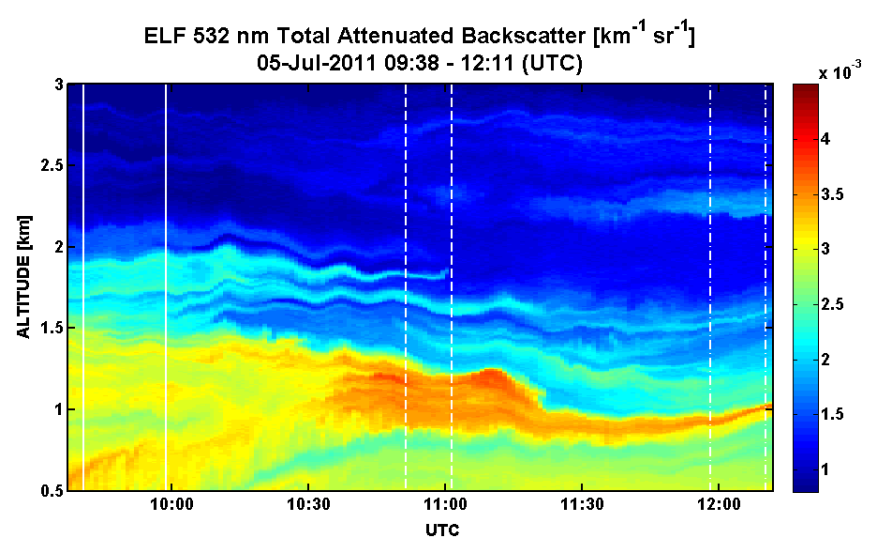

Figure 7. Total attenuated backscatter coefficient cross section obtained with elastic lidar (ELF) at $532 \mathrm{~nm}$ at UMBC on 5 July. Longrange transport of smoke from fires occurring in the southeastern portion of the US was observed. White lines highlight the case studies considered (see Table 1).

in northern Canada (UMBC ALG Smog Blog, 2011). On 5 July, moderate to dense smoke was observed across the southeastern states and long-range transport of smoke from those fires was observed with the lidars that were operating at UMBC during DISCOVER-AQ (Fig. 7). Air mass back trajectories (not shown here) helped us to determine that some layers observed over Baltimore were likely composed of residual smoke from the southern fires. As previously mentioned, this case did not show high AOD values. Out of the cases analyzed, 5 July presented the smallest variation of effective radius values from the lidar retrievals, and this trend was consistent with the P-3B observations and AERONET retrievals, as can be seen in Fig. 6. The retrievals obtained from the lidar data during the first overpass on 5 July (case A) show a small value of $\omega_{0}$ and a large value of $\operatorname{Im}[\mathrm{m}]$ for the top layer $(2.46-2.78 \mathrm{~km})$. The values obtained, $\omega_{0}=0.89 \pm 0.05$ and $\operatorname{Im}[m]=0.013 \pm 0.005$, fall within the range of values observed for biomass burning cases presented by Dubovik et al. (2002): $0.88 \leq \omega_{0}(440 \mathrm{~nm}) \leq 0.94$ and $0.00093 \leq \operatorname{Im}[\mathrm{m}](440 \mathrm{~nm}) \leq 0.021$. However, both retrievals of $\omega_{0}$ and $\operatorname{Im}[m]$ for this particular case also showed large variation, making it a less trustworthy retrieval. Therefore, definite conclusions on the retrieval sensitivity to capture the properties of a smoke layer cannot be drawn in this case. $\operatorname{Re}[m]$ obtained from lidar for this case agrees with values obtained at UMBC and Padonia AERONET stations.

\subsection{July: unusual size parameter case}

The lidar inversion algorithm utilizes Mie theory for the calculations. Therefore, some retrieval sensitivity with respect to the presence of nonspherical aerosol particles is to be expected.

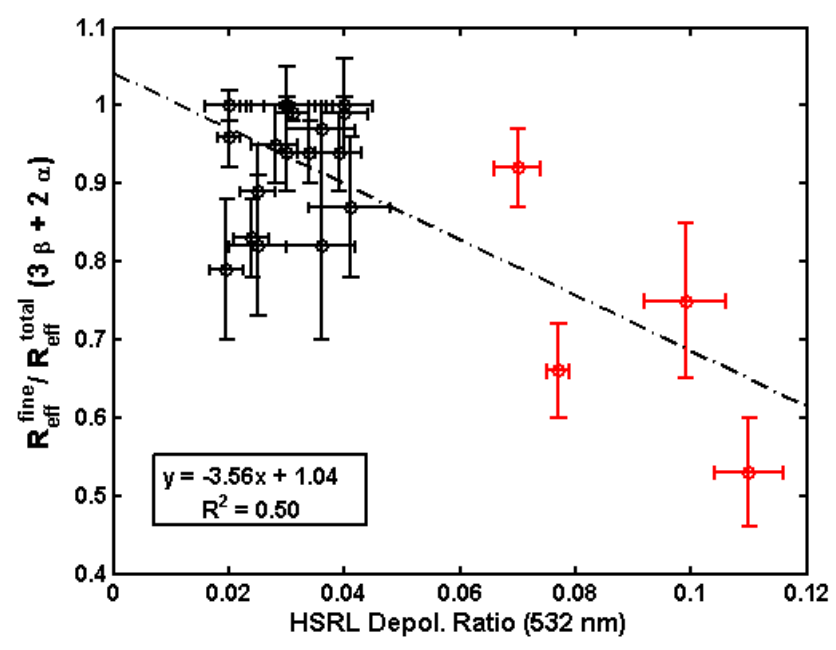

Figure 8. Effective radius fine-to-total mode fraction from lidar retrievals versus total (volume) depolarization ratio at $532 \mathrm{~nm}$ retrieved from HSRL-1. All cases and layers are displayed. Red circles represent 22 July data.

The cases from 22 July presented the lowest values of the effective radius fine-to-total mode fraction $\left(R_{\text {eff }}^{\text {fine }} / R_{\text {eff }}^{\text {total }}\right)$, which translated into larger variation in the individual lidar retrievals, causing the larger error bars observed in cases $\mathrm{G}$ and $\mathrm{H}$ (see Fig. 6). It was later found that $R_{\text {eff }}^{\text {fine }} / R_{\text {eff }}^{\text {total }}$ correlated with the depolarization ratio measurements obtained from the HSRL-1 lidar system. Figure 8 shows two distinct clusters, with data from 22 July in red and the data from other dates in black.

The origin of the nonspherical particles observed in this particular case remains unknown.

\section{Conclusions}

DISCOVER-AQ 2011 provided us with the unique opportunity to test the feasibility of retrieving optical and microphysical properties of aerosols over Baltimore and Washington DC region using a combination of a ground-based backscatter lidar and an airborne HSRL system.

The methodology utilized in this study, although time consuming, was proven to be feasible, and, for the first time, we present daytime retrievals of optical and microphysical properties of aerosols derived from a hybrid multiwavelength lidar data set. In particular, it was also the first study to ever be performed in the United States in which daytime multiwavelength lidar retrievals were obtained and compared both to measurements obtained from airborne in situ instruments and AERONET retrievals.

Comparison of remote sensing retrievals with in situ measurements of aerosols are usually technically challenging due to a number of factors. By definition, remote sensing instruments do not probe aerosols directly, measuring instead 
radiation that is scattered and/or emitted from them, while in situ instruments usually collect aerosols either on filters or chambers in order to make measurements. If not properly characterized and calibrated, in situ instruments may produce different results due to under-sampling as well as changes in temperature and relative humidity in the environment being sampled. Remote sensing instruments, on the other hand, present a different set of potential problems. The instruments must also be well calibrated and characterized, but, in addition to that, the algorithms must be systematically validated to assure the quality of retrievals.

In this study we compared lidar retrievals of effective radius, volume and surface-area concentrations, singlescattering albedo, and complex index of refraction with both AERONET level 1.5 and 2.0 retrievals, which have been extensively studied and validated, as well as aircraft in situ measurements (except $m$ ).

During DISCOVER-AQ 2011, the lidar retrievals showed good agreement with AERONET retrievals for all parameters. The choice of an aerosol layer height (ALH) of $1.5 \mathrm{~km}$ to convert AERONET retrievals of volume and surface-area concentrations from unit area to unit volume was based on continuous lidar observations throughout the campaign and was shown to be reasonable. The AERONET station at UMBC showed a negative bias in terms of singlescattering albedo, which was possibly caused by calibration issues during DISCOVER-AQ, but it was still within 1 standard deviation of other AERONET stations and the lidar retrievals. In general, the values of single-scattering albedo and complex index of refraction obtained from the lidar retrievals in this study showed good agreement with values reported in the literature for the eastern United States during summer.

The airborne in situ measurements showed larger discrepancies with respect to the lidar retrievals, and the reasons, while still speculative, are most likely related to the hydration factors that were not taken into account in this study. Compared to other studies in which hydration factors were considered, the differences observed seem reasonable.

The work here presented is of particular significance not only due to the novel hybrid multiwavelength lidar data set utilized for the inversion of optical and microphysical parameters but also because it is the first study, to our knowledge, in which retrievals were obtained during daytime, and the first to be able to compare results both with AERONET retrievals and in situ aircraft measurements. Similar studies have been conducted in the past, but all microphysical lidar retrievals were obtained at night and only a small number of cases were analyzed. In this study we analyzed 11 case studies.

The combination of different lidar techniques for retrievals of this kind is an attractive idea given that most lidar groups across the globe do not possess multiwavelength lidar systems that are capable of providing a complete $3 \beta+2 \alpha$ data set. With the increasing number of collaborative projects and intensive field campaigns in which a number of different instruments are deployed synergistically, the possibilities of having multiple lidar systems deployed in proximity to each other increase, thus increasing the opportunities of characterizing the aerosols in different areas of the globe.

NASA Langley Research Center (LaRC) recently developed the first airborne multiwavelength HSRL instrument capable of providing a robust $3 \beta+2 \alpha$ data set. HSRL-2 is an upgraded version of the airborne HSRL-1 system utilized in this study and it is capable of providing HSRL measurements at 355 and $532 \mathrm{~nm}$, as well as elastic backscatter measurements at $1064 \mathrm{~nm}$ (Hostetler et al., 2013a, b). In addition to the new instrument, NASA LaRC is also developing a new automated lidar inversion algorithm (Chemyakin et al., 2012) which will allow for more systematic validation of the multiwavelength lidar retrievals.

Acknowledgements. This work was funded by grant NNX10AR38G (NASA DISCOVER-AQ).

Edited by: O. Torres

\section{References}

Andreae, M. O.: The dark side of aerosols, Nature, 409, 671-672, 2001.

Ansmann, A. and Müller, D.: Lidar and Atmospheric Aerosol Particles, in: Lidar: Range-resolved optical remote sensing of the atmosphere, edited by: Weitkamp, C., Springer, 2005.

Balis, D., Giannakaki, E., Müller, D., Amiridis, V., Kelektsoglou, K., Rapsomanikis, S., and Bais, A.: Estimation of the microphysical aerosol properties over Thessaloniki, Greece, during SCOUT-O 3 campaign with the synergy of Raman lidar and Sun photometer data, J. Geophys. Res, 115, D08202 doi:10.1029/2009JD013088, 2010.

Biswas, P., Jones, C. L., and Flagan, R. C.: Distortion of size distributions by condensation and evaporation in aerosol instruments, Aerosol Sci. Technol., 1, 231-246, 1987.

Böckmann, C., Mironova, I., and Müller, D.: Microphysical aerosol parameters from multiwavelength lidar, J. Opt. Soc. Am. A, 22, 518-528, 2005.

Bösenberg, J., Matthias, V., Amodeo, A., Amiridis, V., Ansmann, A., Baldasano, J. M., Balin, I., Balis, D., Böckmann, C., Boselli, A., Carlsson, G., Chaikovsky, A., Chourdakis, G., Comerón, A., De Tomasi, F., Eixmann, R., Freudenthaler, V., Giehl, H., Grigorov, I., Hågård, A., Iarlori, M., Kirsche, A., Kolarov, G., Komguem, L., Kreipl, S., Kumpf, W., Larchevêque, G., Linné, H., Matthey, R., Mattis, I., Mekler, A., Mironova, I., Mitev, V., Mona, L., Müller, D., Music, S., Nickovic, S., Pandolfi, M., Papayannis, A., Pappalardo, G., Pelon, J., Pérez, C., Perrone, R. M., Persson, R., Resendes, D. P., Rizi, V., Rocadenbosch, F., Rodrigues, A., Sauvage, L., Schneidenbach, L., Schumacher, R., Shcherbakov, V., Simeonov, V., Sobolewski, P., Spinelli, N., Stachlewska, I., Stoyanov, D., Trickl, T., Tsaknakis, G., Vaughan, G., Wandinger, U., Wang, X., Wiegner, M., Zavrtanik, M., and Zerefos, C.: EARLINET: A European Aerosol Research Lidar Network to Establish an Aerosol Climatology, Tech. rep., Max Planck Institute for Meteorology, 2003. 
Chemyakin, E., Kolgotin, A., Romanov, A., and Müller, D.: Automated, unsupervised inversion of multiwavelength Raman lidar data: Statistical analysis of microphysical parameters, in: Proceedings of the $26^{26}$ International Laser Radar Conference, Porto Heli, Greece, 2012, S1P-49, 2012.

Comer, J.: UMBC Elastic Backscatter Lidar Facility (ELF): subvisible cirrus cloud and aerosol measurements during ABOVE 2002, Master's thesis, University of Maryland, Baltimore County, 2003.

Dinar, E., Abo Riziq, A., Spindler, C., Erlick, C., Kiss, G., and Rudich, Y.: The complex refractive index of atmospheric and model humic-like substances (HULIS) retrieved by a cavity ring down aerosol spectrometer (CRD-AS), Faraday Discuss., 137, 279-295, 2008.

DISCOVER-AQ: NASA Venture Program, available at: http://www.nasa.gov/mission_pages/discover-aq (last access: 16 September 2014), 2011.

Dubovik, O. and King, M. D.: A flexible inversion algorithm for retrieval of aerosol optical properties from Sun and sky radiance measurements, J. Geophys. Res, 105, 20673-20696, 2000.

Dubovik, O., Smirnov, A., Holben, B., King, M. D., Kaufman, Y. J., Eck, T. F., and Slutsker, I.: Accuracy assessment of aerosol optical properties retrieval from AERONET sun and sky radiance measurements, J. Geophys. Res, 105, 9791-9806, 2000.

Dubovik, O., Holben, B., Eck, T. F., Smirnov, A., Kaufman, Y. J., King, M. D., Tanré, D., and Slutsker, I.: Variability of absorption and optical properties of key aerosol types observed in worldwide locations, J. Atmos. Sci., 59, 590-608, 2002.

Engel-Cox, J. A., Hoff, R. M., Rogers, R., Dimmick, F., Rush, R. C., Szykman, J. J., Al-Saadi, J., Chu, D. A., and Zell, E. R.: Integrating lidar and satellite optical depth with ambient monitoring for 3-dimensional particulate characterization, Atmos. Environ., 40, 8056-8067, 2006.

Gysel, M., Weingartner, E., and Baltensperger, U.: Hygroscopicity of aerosol particles at low temperatures. 2. Theoretical and experimental hygroscopic properties of laboratory generated aerosols, Environ. Sci. Technol., 36, 63-68, 2002.

Hair, J. W., Hostetler, C. A., Cook, A. L., Harper, D. B., Ferrare, R. A., Mack, T. L., Welch, W., Izquierdo, L. R., and Hovis, F. E.: Airborne High Spectral Resolution Lidar for profiling aerosol optical properties, Appl. Opt., 47, 6734-6752, 2008.

Hansen, J. E., Sato, M., and Ruedy, R.: Radiative forcing and climate response., J. Geophys. Res, 102, 6821-6864, 1997.

Haywood, J. M. and Ramaswamy, V.: Global sensitivity studies of the direct radiative forcing due to anthropogenic sulfate and black carbon aerosols, J. Geophys. Res, 103, 6043-6058, 1998.

Hoff, R. M., Berkoff, T., Delgado, R., Sawamura, P., Ferrare, R. A., Hair, J., Hostetler, C., Rogers, R., Obland, M., Anderson, B., Crawford, J., and Holben, B.: DISCOVER-AQ: Determining the relationship between satellite retrieved column AOD, extinction profiles and surface $\mathrm{PM}_{2.5}$, in: Proceedings of $26^{\text {th }}$ International Laser Radar Conference, Porto Heli, Greece, 2012.

Holben, B. N., Eck, T. F., Slutsker, I., Tanré, D., Buis, J. P., Setzer, A., Vermote, E., Reagan, J. A., Kaufman, Y. J., Nakajima, T., Lavenu, F., Jankowiak, I., and Smirnov, A.: AERONET - A federated instrument network and data archive for aerosol characterization, Remote Sens. Environ., 66, 1-16, 1998.

Holben, B. N., Eck, T. F., Slutsker, I., Smirnov, A., Sinyuk, A., Schafer, J., Giles, D., and Dubovik, O.: AERONET's Version 2.0 quality assurance criteria, in: Proc. SPIE 6408, Remote Sens. Atmos. Clouds, 64080Q, 64080Q-64080Q-14, 2006.

Holben, B. N., Eck, T., Schafer, J., Giles, D., and Sorokin, M.: Distributed Regional Aerosol Gridded Observation Networks (DRAGON) White Paper, available at: http://aeronet.gsfc.nasa.gov/new_web/Documents/DRAGON_ White_Paper_A_system_of_experiment.pdf (last access: 16 September 2014), 2011.

Hostetler, C. A., Ferrare, R. A., Hair, J. W., Cook, A. L., Harper, D. B., Rogers, R. R., Müller, D., Burton, S. P., Obland, M. D., Scarino, A. J., Schmid, B., Fast, J., Berg, L., Flynn, C., Cairns, B., Russell, P. B., Redemann, J., and Shinozuka, Y.: Airborne Multi-wavelength High Spectral Resolution Lidar Observations and Applications from TCAP, available at: http://asr. science.energy.gov/meetings/stm/posters/view?id=797 (last access: 16 September 2014), 2013a.

Hostetler, C. A. et al.: Airborne Multi-wavelength High Spectral Resolution Lidar Observations and Applications from TCAP, available at: http://asr.science.energy.gov/meetings/stm/2013/ presentations/Ferrare-TCAP-HSRL-03192013.pdf (last access: 16 September 2014), $2013 b$.

Jacobson, M.: Air Pollution and Global Warming: History, Science, and Solutions, Cambridge University Press, 2012.

Kaufman, Y. J., Tanré, D., Remer, L. A., Vermote, E. F., Chu, A., and Holben, B. N.: Operational remote sensing of tropospheric aerosol over land from EOS moderate resolution imaging spectroradiometer, J. Geophys. Res, 102, 17051-17067, 1997.

Knapp, K. R.: Quantification of aerosol signal in GOES 8 visible imagery over the United States, J. Geophys. Res.-Atmos., 107, doi:10.1029/2001JD002001, 2002.

Leaitch, W. and Isaac, G.: Tropospheric aerosol size distributions from 1982 to 1988 over eastern North America, Atmos. Environ., 25, 601-619, 1991.

Liu, H., Remer, L. A., Huang, J., Huang, H.-C., Kondragunta, S., Laszlo, I., Oo, M., and Jackson, J. M.: Preliminary evaluation of S-NPP VIIRS aerosol optical thickness, J. Geophys. Res.Atmos., 119, 3942-3962, doi:10.1002/2013JD020360, 2014.

Lopatin, A., Dubovik, O., Chaikovsky, A., Goloub, P., Lapyonok, T., Tanré, D., and Litvinov, P.: Enhancement of aerosol characterization using synergy of lidar and sun-photometer coincident observations: the GARRLiC algorithm, Atmos. Meas. Tech., 6, 2065-2088, doi:10.5194/amt-6-2065-2013, 2013.

Michel Flores, J., Bar-Or, R. Z., Bluvshtein, N., Abo-Riziq, A., Kostinski, A., Borrmann, S., Koren, I., Koren, I., and Rudich, Y.: Absorbing aerosols at high relative humidity: linking hygroscopic growth to optical properties, Atmos. Chem. Phys., 12, 5511-5521, doi:10.5194/acp-12-5511-2012, 2012.

Müller, D., Wandinger, U., Althausen, D., Mattis, I., and Ansmann, A.: Retrieval of physical particle properties from lidar observations of extinction and backscatter at multiple wavelengths, Appl. Optics, 37, 2260-2263, 1998.

Müller, D., Wandinger, U., and Ansmann, A.: Microphysical particle parameters from extinction and backscatter lidar data by inversion with regularization: Theory, Appl. Opt., 38, 2346-2357, 1999a.

Müller, D., Wandinger, U., and Ansmann, A.: Microphysical particle parameters from extinction and backscatter lidar data by inversion with regularization: simulation, Appl. Optics, 38, 23582368, 1999b. 
Müller, D., Wagner, F., Wandinger, U., Ansmann, A., Wendisch, M., Althausen, D., and von Hoyningen-Huene, W.: Microphysical particle parameters from extinction and backscatter lidar data by inversion with regularization: Experiment, Appl. Optics, 39, 1879-1892, 2000.

Müller, D., Wandinger, U., Althausen, D., and Fiebig, M.: Comprehensive particle characterization from three-wavelength Ramanlidar observations: Case study, Appl. Optics, 40, 4863-4869, 2001.

Müller, D., Franke, K., Ansmann, A., Althausen, D., and Wagner, F.: Indo-Asian pollution during INDOEX: Microphysical particle properties and single-scattering albedo inferred from multiwavelength lidar observations, J. Geophys. Res, 108, 4600, doi:10.1029/2003JD003538, 2003.

Müller, D., Mattis, I., Wandinger, U., Ansmann, A., Althausen, D., and Stohl, A.: Raman lidar observations of aged Siberian and Canadian forest fire smoke in the free troposphere over Germany in 2003: Microphysical particle characterization, J. Geophys. Res.-Atmos., 110, L20811, doi:10.1029/2004JD005756, 2005.

Müller, D., Tesche, M., Eichler, H., Engelmann, R., Althausen, D., Ansmann, A., Cheng, Y. F., Zhang, Y. H., and Hu, M.: Strong particle light absorption over the Pearl River Delta (south China) and Beijing (north China) determined from combined Raman lidar and Sun photometer observations, Geophys. Res. Lett., 33, L20811, doi:10.1029/2006GL027196, 2006.

Müller, D., Kolgotin, A., Mattis, I., Petzold, A., and Stohl, A.: Vertical profiles of microphysical particle properties derived from inversion with two-dimensional regularization of multiwavelength Raman lidar data: Experiment, Appl. Optics, 50, 2069-2079, 2011.

Murayama, T., Müller, D., Wada, K., Shimizu, A., Sekiguchi, M., and Tsukamoto, T.: Characterization of Asian dust and Siberian smoke with multi-wavelength Raman lidar over Tokyo, Japan in spring 2003, Geophys. Res. Lett., 31, L23103, doi:10.1029/2004GL021105, 2004.

Noh, Y. M.: Single scattering albedo profiling of mixed Asian dust plumes with multiwavelength Raman lidar, Atmos. Environ., 95, 305-317, doi:10.1016/j.atmosenv.2014.06.028, 2014.

Noh, Y. M., Müller, D., Shin, D. H., Lee, H., Jung, J., Lee, K. H., Cribb, M., Li, Z., and Kim, Y. J.: Optical and microphysical properties of severe haze and smoke aerosol measured by integrated remote sensing techniques in Gwangju, Korea, Atmos. Environ., 43, 879-888, 2009.

Noh, Y. M., Müller, D., Mattis, I., Lee, H., and Kim, Y. J.: Vertically resolved light-absorption characteristics and the influence of relative humidity on particle properties: Multiwavelength Raman lidar observations of East Asian aerosol types over Korea, J. Geophys. Res.-Atmos., 116, D06206, doi:10.1029/2010JD014873, 2011.

Pahlow, M., Müller, D., Tesche, M., Eichler, H., Feingold, G., Eberhard, W. L., and Cheng, Y. F.: Retrieval of aerosol properties from combined multiwavelength lidar and sunphotometer measurements, Appl. Optics, 45, 7429-7442, 2006.

Pérez-Ramírez, D., Whiteman, D. N., Veselovskii, I., Kolgotin, A., Korenskiy, M., and Alados-Arboledas, L.: Effects of systematic and random errors on the retrieval of particle microphysical properties from multiwavelength lidar measurements using in- version with regularization, Atmos. Meas. Tech., 6, 3039-3054, doi:10.5194/amt-6-3039-2013, 2013.

Redemann, J., Turco, R. P., Liou, K. N., Russell, P. B., Bergstrom, R. W., Schmid, B., Livingston, J. M., Hobbs, P. V., Hartley, W. S., Ismail, S., Ferrare, R. A., and Browell, E. V.: Retrieving the vertical structure of the effective aerosol complex index of refraction from a combination of aerosol in situ and remote sensing measurements during TARFOX, J. Geophys. Res.-Atmos., 105, 9949-9970, 2000.

Redemann, J., Russell, P. B., and Hamill, P.: Dependence of aerosol light absorption and single-scattering albedo on ambient relative humidity for sulfate aerosols with black carbon cores, J. Geophys. Res, 106, 27485-27495, 2001.

Remer, L. A., Gassó, S., Hegg, D. A., Kaufman, Y. J., and Holben, B. N.: Urban/industrial aerosol: Ground-based Sun/sky radiometer and airborne in situ measurements, J. Geophys. Res.-Atmos., 102, 16849-16859, 1997.

Schafer, J. S., Eck, T. F., Holben, B. N., Thornhill, K. L., Anderson, B. E., Sinyuk, A., Giles, D. M., Winstead, E. L., Ziemba, L. D., Beyersdorf, A. J., Kenny, P. R., Smirnov, A., and Slutsker, I.: Intercomparison of aerosol single scattering albedo derived from AERONET surface radiometers and LARGE in-situ aircraft profiles during the 2011 DRAGON-MD and DISCOVERAQ experiments, J. Geophys. Res.-Atmos., 119, 7439-7452, doi:10.1002/2013JD021166, 2014.

Sjogren, S., Gysel, M., Weingartner, E., Baltensperger, U., Cubison, M., Coe, H., Zardini, A., Marcolli, C., Krieger, U., and Peter, T.: Hygroscopic growth and water uptake kinetics of two-phase aerosol particles consisting of ammonium sulfate, adipic and humic acid mixtures, J. Aerosol Sci., 38, 157-171, 2007.

Sugimoto, N. and Uno, I.: Observation of Asian dust and air pollution aerosols using a network of ground-based lidars (ADNet): realtime data processing for validation/assimilation of chemical transport models, IOP Conf. Ser.: Earth Environ. Sci., 7, 012003, doi:10.1088/1755-1307/7/1/012003, 2009.

Tanré, D., Kaufman, Y. J., Herman, M., and Mattoo, S.: Remote Sensing of aerosol properties over oceans using the MODIS/EOS spectral radiances, J. Geophys. Res, 102, 16971-16988, 1997.

Tesche, M., Müller, D., Ansmann, A., Hu, M., and Zhang, Y.: Retrieval of microphysical properties of aerosol particles from onewavelength Raman lidar and multiwavelength Sun photometer observations, Atmos. Environ., 42, 6398-6404, 2008.

Tikhonov, A. and Arsenin, V.: Solutions of ill-posed problems, Scripta Series in Mathematics, Winston, 1977.

Twomey, S.: The influence of pollution on the shortwave albedo of clouds, J. Atmos. Sci., 34, 1149-1154, 1977.

UMBC ALG Smog Blog: U.S. Air Quality, available at: http://alg. umbc.edu/usaq/archives/2011_07.html (last access: 19 September 2014), 2011.

Veselovskii, I., Kolgotin, A., Griaznov, V., Müller, D., Wandinger, U., and Whiteman, D. N.: Inversion with regularization for the retrieval of tropospheric aerosol parameters from multiwavelength lidar sounding, Appl. Optics, 41, 3685-3699, 2002.

Veselovskii, I., Kolgotin, A., Griaznov, V., Müller, D., Franke, K., and Whiteman, D. N.: Inversion of multiwavelength Raman lidar data for retrieval of bimodal aerosol size distribution, Appl. Opt., 43, 1180-1195, 2004.

Veselovskii, I., Whiteman, D. N., Kolgotin, A., Andrews, E., and Korenskii, M.: Demonstration of aerosol property profiling by 
multiwavelength lidar under varying relative humidity conditions, J. Atmos. Ocean. Technol., 26, 1543-1557, 2009.

Veselovskii, I., Dubovik, O., Kolgotin, A., Korenskiy, M., Whiteman, D. N., Allakhverdiev, K., and Huseyinoglu, F.: Linear estimation of particle bulk parameters from multi-wavelength lidar measurements, Atmos. Meas. Tech., 5, 1135-1145, doi:10.5194/amt-5-1135-2012, 2012a.

Veselovskii, I., Whiteman, D. N., Kolgotin, A., Korenskiy, M., and Perez-Ramirez, D.: Retrieval of height-temporal distributions of particle parameters from multiwavelength lidar measurements during DISCOVER-AQ 2011 campaign, in: Proceedings of the $26^{26}$ International Laser Radar Conference, Porto Heli, Greece, 2012, S3O-14, 2012 b.

Veselovskii, I., Whiteman, D. N., Korenskiy, M., Kolgotin, A., Dubovik, O., Perez-Ramirez, D., and Suvorina, A.: Retrieval of spatio-temporal distributions of particle parameters from multiwavelength lidar measurements using the linear estimation technique and comparison with AERONET, Atmos. Meas. Tech., 6, 2671-2682, doi:10.5194/amt-6-2671-2013, 2013.

Wagner, J., Ansmann, A., Wandinger, U., Seifert, P., Schwarz, A., Tesche, M., Chaikovsky, A., and Dubovik, O.: Evaluation of the Lidar/Radiometer Inversion Code (LIRIC) to determine microphysical properties of volcanic and desert dust, Atmos. Meas. Tech., 6, 1707-1724, doi:10.5194/amt-6-1707-2013, 2013.
Wandinger, U., Müller, D., Böckmann, C., Althausen, D., Matthias, V., Bösenberg, J., Weiß, Fiebig, M., Wendisch, M., Stohl, A., and Ansmann, A.: Optical and microphysical characterization of biomass-burning and industrial-pollution aerosols from multiwavelength lidar and aircraft measurements, J. Geophys. Res, 107, 8125, doi:10.1029/2000JD000202, 2002.

Welton, E. J., Campbell, J. R., Spinhirne, J. D., and Scott, V. S.: Global monitoring of clouds and aerosols using a network of micro-pulse lidar systems, in: Lidar Remote Sensing for Industry and Environmental Monitoring, edited by: Singh, U. N., Itabe, T., and Sugimoto, N., Proc. SPIE, 4153, 151-158, 2001.

Winkler, P.: The growth of atmospheric aerosol particles with relative humidity, Physica Scripta, 37, 223-230, 1988.

Ziemba, L. D., Lee Thornhill, K., Ferrare, R., Barrick, J., Beyersdorf, A. J., Chen, G., Crumeyrolle, S. N., Hair, J., Hostetler, C., Hudgins, C., Obland, M., Rogers, R., Scarino, A. J., Winstead, E. L., and Anderson, B. E.: Airborne observations of aerosol extinction by in situ and remote-sensing techniques: Evaluation of particle hygroscopicity, Geophys. Res. Lett., 40, 417-422, doi:10.1029/2012GL054428, 2013. 